\title{
Metabolism and fate of organophosphate ester (OPE) contaminants in rainbow trout (Oncorhynchus mykiss) using in vitro lab-based studies
}

\author{
by \\ Delaney N. Large
}

A thesis submitted to the Faculty of Graduate and Postdoctoral Affairs in partial fulfillment of the requirements for the degree of

Master of Science

in

Biology, Specialization in Chemical and Environmental Toxicology

Carleton University

Ottawa, Ontario

C 2019, Delaney N. Large 


\begin{abstract}
Due to ubiquitous use of organophosphate esters (OPEs) as flame retardants and plasticizers, they have been found at high concentrations in a variety of environmental media while having low or non-detectable levels in biota, including fish. The exposure and fate of OPEs in fish depends on understanding the toxicokinetics, though studies on OPE metabolism are lacking. A model in vitro microsomal-based metabolism assay for rainbow trout (Oncorhynchus mykiss) was utilized to investigate OPE metabolism. Metabolic depletion was only noted for 2 alkyl OPEs and formation of corresponding diester metabolites was low, indicating other unidentified metabolites were formed. Comparison with avian and mammalian models showed fish generally had slower and less complete metabolism, illustrating species-specific differences in biotransformation. Structure also influenced OPE metabolism in that bulky, aryl OPEs were not metabolized. These results provide important information of toxicokinetic processes that can affect the exposure and fate of OPEs in rainbow trout.
\end{abstract}




\section{Acknowledgements}

Over the course of completing my Master's degree, I have come to appreciate and cherish the support provided to me by a handful of truly wonderful people. First, I must thank my supervisors Dr. Rob Letcher and Dr. Bill Willmore. The process of getting to this point may not have been the smoothest or easiest but your unwavering support and patience gave me the push I needed to complete writing this thesis. I feel privileged to have been under the tutelage of two exceptional members of the scientific community. My growth as a scientist and as a person over the last three years could not have happened were it not for your encouragement. Rob and Bill, thank you.

I would also like to thank the Organic Contaminants Research Laboratory (OCRL) group. Shaogang Chu has always been a fountain of knowledge and my confidence in using ultra-high performance liquid chromatography (UPLC) can solely be attributed to his guidance. Thank you to David Blair and Luke Periard for fielding my many questions of "where can I find $x$ ?" or "can we please order more of $y$ ?". Your willingness and ability to find solutions for lab-based problems is something I aspire to improve myself. I would also like to thank Adelle Strobel for showing me the workings of our lab in a way that was fun and interesting. Your guidance on the in vitro assay was an indispensable part of this project and your cheery disposition truly made my day. Tristan, Adam, and Katie, many thanks to you as well for the countless stories, laughs, and lunches shared throughout this experience, it wouldn't have been the same without you.

In both the decision to attend and the transition to graduate school, three people have been instrumental. Dr. Shannon Timmons and Dr. Julie Zwiesler-Vollick, it is 
because of your support and encouragement that I am where I am today. You both gave me confidence in myself and my scientific abilities. I also wish to thank Dr. Tony Scheuhammer for pointing me in the direction of Carleton University and Rob's lab group, I would likely still be in Michigan if it weren't for your advice. Thanks are also in order for your homemade bread recipes, very tasty!

Thank you to my OCVL volleyball team, Jenn, Elise, Kay, Sue, Sheila, Jeannie, Nadine, and Josie for a much-needed weekly break from academia (go Six Pack!). Thanks are also in order for my American volleyball friends. Though we may be separated by international borders, you've always managed to know when a phone call or FaceTime was needed. Mary, Brenna, Brittany, Bri, and Taryn my appreciation for you knows no bounds. I would like to thank my parents and my brother. The three of you have always been my biggest fans and it's truly wonderful to know that you're supporting me in all my endeavours, no matter how crazy. Lastly, I'd like to thank my partner Colin and our sweet cats, Milo and Duchess. No matter how hard of a day I've had, your endless reassurance and comfort never ceases to lift my spirits.

This project was funded by the Natural Sciences and Engineering Research Council of Canada (NSERC Discover Grants to R.J.L. and W.G.W.) and the NSERC Collaborative Research and Training Experience Program - Research in Environmental, Analytical Chemistry and Toxicology (CREATE - REACT) program (to R.J.L. and W.G.W).

"A man can only stumble for so long before he either falls or stands up straight." - Brandon Sanderson, The Well of Ascension 


\section{Table of Contents}

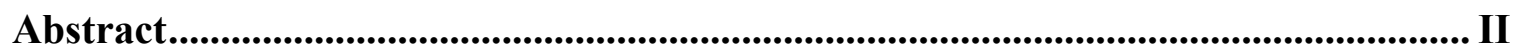

Acknowledgements ..........................................................................................................................III

Table of Contents ............................................................................................................ V

List of Tables ........................................................................................................................ VII

List of Figures.............................................................................................................................VIII

List of Abbreviations ...........................................................................................................IX

Chapter 1: General Introduction ............................................................................................. 1

1.1 Flame Retardant Chemicals and Organophosphate Esters ......................................... 1

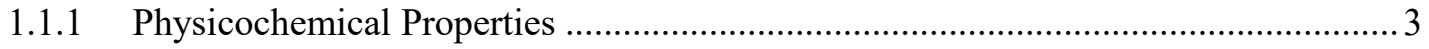

1.1.2 Qualitative and Quantitative Analytical Determination of OPEs in Biological

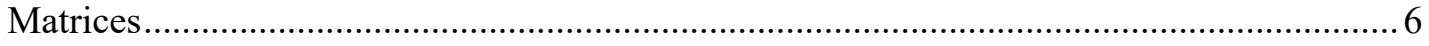

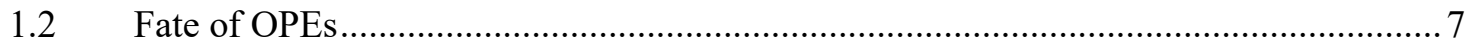

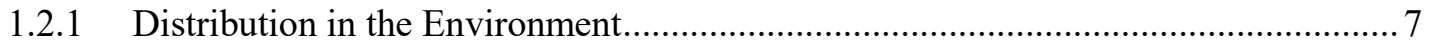

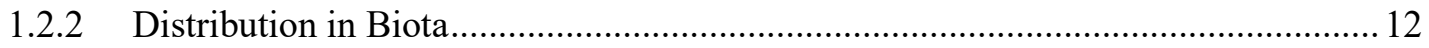

1.3 Absorption, Distribution, Metabolism, and Excretion (ADME) …........................... 15

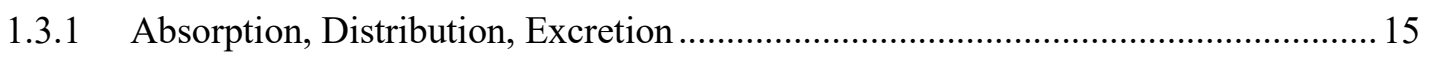

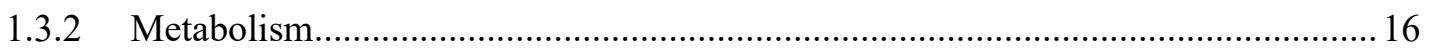

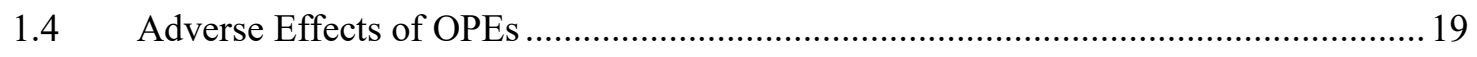

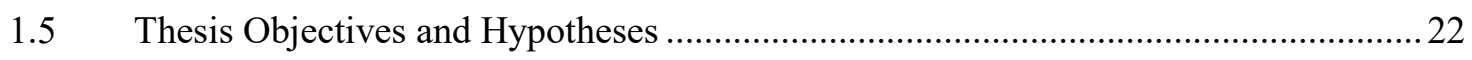

Chapter 2: Materials and Methods ............................................................................... 25

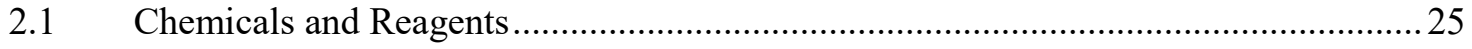

2.2 In Vitro Biotransformation Assay for OPEs........................................................25

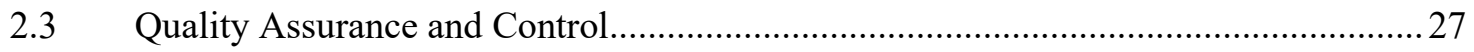


2.4 Determination of OP Triester Depletion and OP Diester Formation

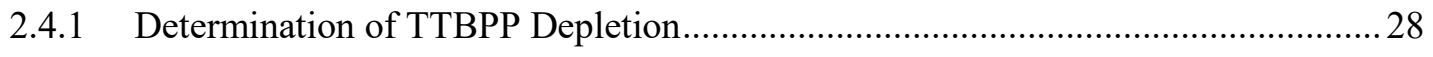

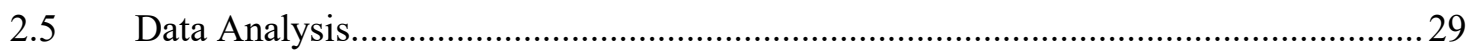

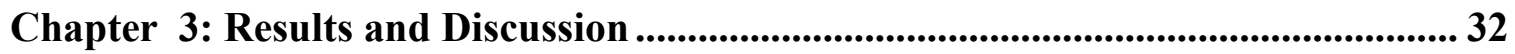

3.1 In vitro OP Triester Metabolism and OP Diester Formation......................................... 32

Chapter 4: Conclusions and Future Directions........................................................ 43

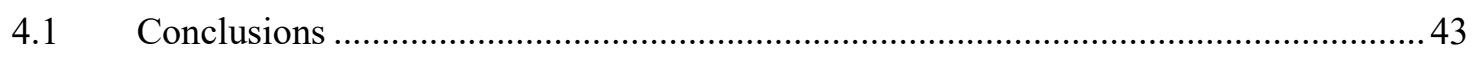

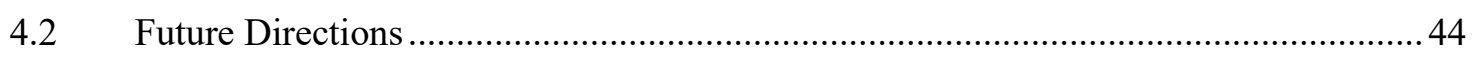

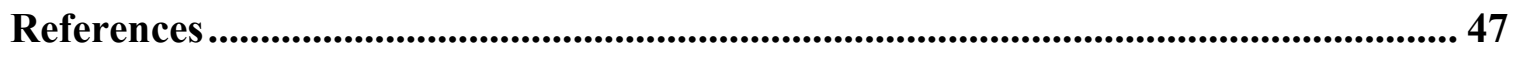




\section{List of Tables}

Table 1.1 Summary of key physicochemical characteristics describing some current - use organophosphate triesters and diesters for the present study. Log Kow values denoted with

* are predictions from Chemspider, all other values are from ChemIDplus. 5

Table 1.2 LD50 of selected OPEs in recent reports. LD50 values are unavailable for TTBPP, DPHP, DNBP, BBOEP, BDCIPP, and DEHP. All values are from PubChem.. 21

Table 2.1. Operating parameters of MS/MS for in vitro analysis including the multiple reaction monitoring $(\mathrm{MRM})$ transitions and mass-labelled internal standards. 31

Table 3.1 Organophosphate (OP) triester depletion and OP diester formation in metabolism assays with rainbow trout liver microsomes. Administered concentration of each OP triester was $2 \mu \mathrm{M}$. Names and abbreviations of the OP triesters and OP diesters

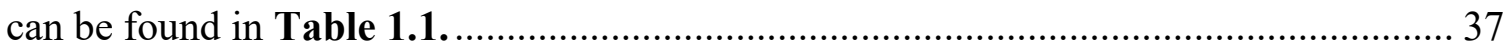




\section{List of Figures}

Figure 1.1 General structures of organophosphate triesters and organophosphate diesters.

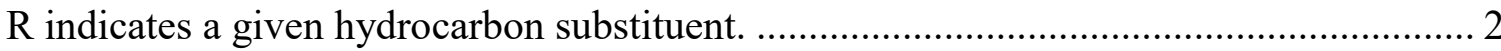

Figure 1.2 Chemical structures of all target organophosphate triesters and diesters in this thesis. Full compound names, CAS identification numbers, molecular mass, $\log \mathrm{K}_{o w}$, and water solubility can be found in Table 1.1. Hydrogen atoms have been omitted for clarity.

Figure 3.1 In vitro metabolic depletion of OP triesters (solid line and solid symbols) and formation of OP diesters (dashed line and open symbols) over a 100 minute assay with rainbow trout microsomes. Every data point is the mean of triplicate assays $(\mathrm{n}=3)$ conducted on $\mathrm{n}=2$ days for a total of $\mathrm{n}=6$ replicates. Error bars represent the $\pm \mathrm{SEM}$ and are omitted where the error bar is shorter than the size of the symbol. The time points when OP triester depletion or OP diester formation significantly differ $(p<0.05)$ from the concentration at one minute are denoted with an asterisk. The concentration at 1 minute was used instead of the concentration at 0 minutes because it better reflected the dosed concentration. 


\section{List of Abbreviations}

\begin{tabular}{|c|c|}
\hline ADME & absorption, distribution, metabolism, excretion \\
\hline ANOVA & analysis of variance \\
\hline BBOEHEP & bis(2-butoxyethyl) hydroxyethyl phosphate \\
\hline BBOEP & bis(1,2-butoxyethyl) phosphate \\
\hline BCEP & bis(2-chloroethyl) phosphate \\
\hline BCIPP & bis(1-chloro-2-propyl) phosphate \\
\hline BDCIPP & bis(1,3-dichloro-2-propyl) phosphate \\
\hline CAS No. & chemical abstract service registry number \\
\hline CREATE & Collaborative Research and Training Experience Program \\
\hline CYP & cytochrome P450 enzyme \\
\hline DEHP & di(2-ethylhexyl) phosphate \\
\hline DNBP & di-n-butyl phosphate \\
\hline DPHP & diphenyl phosphate \\
\hline $\mathrm{dw}$ & dry weight \\
\hline EHDPP & 2-ethylhexyl diphenyl phosphate \\
\hline GAPS & Global Atmospheric Passive Sampling \\
\hline GC-MS & gas chromatography-mass spectrometry \\
\hline HBCDD & hexabromocyclododecane \\
\hline HPLC & high performance liquid chromatography \\
\hline $\mathrm{K}_{\mathrm{M}}$ & Michaelis constant \\
\hline Kow & octanol-water partition coefficient \\
\hline LOD & limit of detection \\
\hline lw & lipid weight \\
\hline MLOD & method limit of detection \\
\hline MLOQ & method limit of quantification \\
\hline MS/MS & tandem mass spectrometry \\
\hline NADPH & nicotinamide adenine dinucleotide phosphate \\
\hline n.d. & not detected \\
\hline NSERC & Natural Sciences and Engineering Research Council \\
\hline OCRL & Organic Contaminants Research Laboratory \\
\hline
\end{tabular}




$\begin{array}{ll}\text { OPE } & \text { organophosphate ester } \\ \text { PAC } & \text { powdered activated carbon } \\ \text { PBDE } & \text { polybrominated diphenyl ether } \\ \text { PCB } & \text { polychlorinated biphenyl } \\ \text { POP } & \text { persistent organic pollutant } \\ \text { RDP } & \text { resorcinol bis(diphenyl phosphate) } \\ \text { REACT } & \text { Research in Environmental, Analytical Chemistry and Toxicology } \\ \text { T4IPPP } & \text { tris(4-isopropylphenyl) phosphate } \\ \text { TBOEP } & \text { tris(2-butoxyethyl) phosphate } \\ \text { TCEP } & \text { tris(2-chloroethyl) phosphate } \\ \text { TCP } & \text { tri- } p \text {-cresyl phosphate } \\ \text { TDCIPP } & \text { tris(1,3-dichloro-2-propyl) phosphate } \\ \text { TEP } & \text { triethyl phosphate } \\ \text { TEHP } & \text { tris(2-ethylhexyl) phosphate } \\ \text { TNBP } & \text { tri-n-butyl phosphate } \\ \text { TPHP } & \text { triphenyl phosphate } \\ \text { TPP } & \text { tripropyl phosphate } \\ \text { TTBPP } & \text { tris(p-tert-butylphenyl) phosphate } \\ \text { UPLC } & \text { wltra-high performance liquid chromatography } \\ \text { WW } & \text { wastewater treatment plant } \\ \text { WWTP } & \end{array}$




\section{Chapter 1: General Introduction}

\subsection{Flame Retardant Chemicals and Organophosphate Esters}

In today's homes and public spaces, flammability concerns are well warranted. Increased use of plastics, foams, synthetic fiber-base fillings, and electronics bring an increased risk of fire as many of these polymers can be highly flammable. Industry flammability standards, such as California's Technical Bulletin 117, were implemented in an effort to reduce fires and increase average escape time (US EPA, 2007) and, as a result, production and use of flame retardants has become common practice to meet flammability standards in various consumer goods, textiles, furniture, electronics, and plastics.

Introduction of and subsequent amendments to the Stockholm Convention Annex A list of Persistent Organic Pollutants (POPs) have resulted in restriction of multiple flame retardant chemicals, including hexabromocyclododecane (HBCDD), polychlorinated biphenyls (PCBs), and some polybrominated diphenyl ethers (PBDEs) due to concerns regarding bioaccumulation and persistence in the environment and potential hazardous health effects. As brominated flame retardants, especially penta-, octa-, and deca-BDEs, are phased out across the world, there has been a concerted effort to find alternatives that are effective from both a cost and performance basis (United Nations Environment Programme, 2017). Consequently, the use of organophosphate esters (OPEs) serving as industrial lubricants, plasticizers, and flame retardants has increased significantly (van der Veen \& de Boer, 2012). In 2015, worldwide consumption of flame retardants reached a volume of 2.49 million tons with growth expected to exceed 4.0 million tons by 2025 at a market value of \$11.96 billion USD (Freedonia, 2017). Market volume of OPEs reached 620,000 tons in 2013 , accounting for $30 \%$ of the global total and in 2015, OPEs surpassed 
brominated flame retardants in market size (Freedonia, 2017; Sühring et al., 2016). With such market growth comes the need for toxicological data to ensure regrettable substitutions are avoided.

OPEs are composed of a central phosphate molecular group with ester linkages that can be halogenated, alkylated, or arylated (van der Veen \& de Boer, 2012) (Figure 1.1).

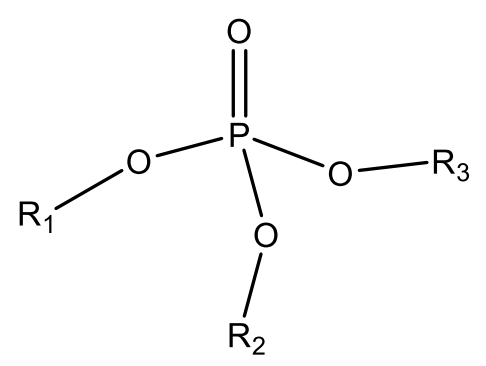

Organophosphate Triester

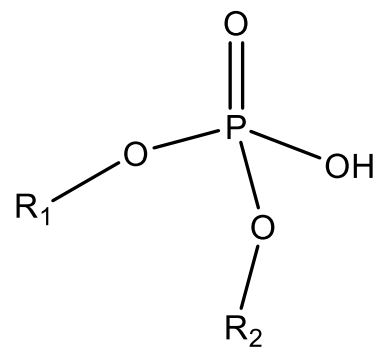

Organophosphate Diester

Figure 1.1 General structures of organophosphate triesters and organophosphate diesters. R indicates a given hydrocarbon substituent.

OPEs used as additives to industrial and consumer products are not chemically bound. The specific mechanism of flame retardancy varies based on composition: the phosphorus interferes with the combustion process by physically insulating available fuel sources with a fire-resisting char layer, and halogen containing OPEs interact with the gas phase of the fire cycle trapping free radicals and interrupting the chemical chain reaction leading to flame formation (van der Veen \& de Boer, 2012). OP diesters share similar structure with the exception that one of the alkyl ester groups is replaced by a hydroxyl group, creating a phosphoric acid. 


\subsubsection{Physicochemical Properties}

Because of the variety of potential ester linkages, OPEs have a wide range of physical and chemical properties (Table 1). Octanol-water partition coefficients (log $\left.K_{\mathrm{OW}}\right)$ for OPEs have a broad range, though most currently used OPEs have log Kow values between 1 and 5, indicating lipophilic tendencies (Chu \& Letcher, 2015; Yadav et al., 2018). Size and polarity also have a role in determining the physicochemical properties of OPEs. Generally, solubility decreases with increasing molecular weight, with the exception of halogenated OPEs where no relationship has been observed. Additionally, as molecular weight increases, $\log K_{O W}$ values also increase (van der Veen \& de Boer, 2012). Recently, it was demonstrated (Wang et al., 2018a; Wang et al., 2018b) that successful OPE removal from water can be done via adsorption to powdered activated carbon (PAC), shedding light on interfacial behavior of common OPEs in aquatic environments where molecular size and hydrophobicity greatly influence the sorption rate. In aqueous solutions, OPEs are generally stable beyond $\mathrm{pH} 11$, and base-catalysed hydrolysis of OP triesters results in the formation of OP diesters (Su et al., 2016a). OPE stability in basic solutions is dependent on substituent groups with alkyl moieties being the most stable followed by chlorinated alkyl moieties and lastly aryl moieties. Additionally, mineral-catalyzed hydrolysis of OPEs has been demonstrated with Fe(III) hydroxide, suggesting that such reactions may be widespread in Fe-rich soils (Fang et al., 2018).

Several studies have demonstrated microbial degradation of OPEs. In heatsterilized samples of water from the Mississippi river, no degradation or loss of OPEs was detected, but complete degradation of OPE occurred within 7 days in untreated samples (Saeger et al., 1979). OPE degradation has also been documented in sewage sludge samples 
and seawater, demonstrating that OPEs can be used as a source of phosphorus under limiting conditions (Pang et al., 2018; Vila-Costa et al., 2019). The biodegradability of individual OPEs is dependent on physicochemical properties. In alkyl OPEs, potential for biodegradation decreases with chain length as does increasing the size and number of substituents on the phenyl rings of aryl OPEs. Halogenated OPEs are often less biodegradable than nonhalogenated analogues, potentially a result of steric hindrance where a larger leaving group sterically inhibits nucleophilic attack of the P center (Fang et al., 2018). 
Table 1.1 Summary of key physicochemical characteristics describing some current - use organophosphate triesters and diesters for the present study. Log $K_{\mathrm{OW}}$ values denoted with * are predictions from Chemspider, all other values are from ChemIDplus.

\begin{tabular}{|c|c|c|c|c|c|}
\hline Abbreviation & OPE & CAS Number & $\begin{array}{c}\text { Molar Mass } \\
(\mathrm{g} / \mathrm{mol})\end{array}$ & Log Kow & $\begin{array}{c}\text { Water } \\
\text { Solubility } \\
\left(\mathrm{mg} / \mathrm{L} @ 25^{\circ} \mathrm{C}\right) \\
\end{array}$ \\
\hline ТРНP & Triphenyl phosphate & $115-86-6$ & 326.3 & 4.59 & 1.9 \\
\hline DPHP & Diphenyl phosphate & $838-85-7$ & 250.2 & 2.88 & 82.4 \\
\hline TNBP & tri-n-butyl phosphate & $126-73-8$ & 266.3 & 4 & 280 \\
\hline DNBP & di-n-butyl phosphate & $107-66-4$ & 210.2 & 2.29 & $1.72 \mathrm{E}+04$ \\
\hline TBOEP & $\begin{array}{l}\text { tris(2-butoxyethyl) } \\
\text { phosphate }\end{array}$ & $78-51-3$ & 398.4731 & 3.75 & 1100 \\
\hline BBOEP & $\begin{array}{c}\text { bis(2-butoxyethyl) } \\
\text { phosphate }\end{array}$ & - & $297.3 *$ & $2.22 *$ & - \\
\hline TDCIPP & $\begin{array}{l}\text { tris(1,3-dichloro-2- } \\
\text { propyl) phosphate }\end{array}$ & $13674-87-8$ & 430.9 & 3.65 & 7 \\
\hline BDCIPP & $\begin{array}{l}\text { bis(1,3-dichloro-2- } \\
\text { propyl) phosphate }\end{array}$ & $72236-72-7$ & 319.935 & $2.18 *$ & $130 *$ \\
\hline TEHP & $\begin{array}{c}\text { tris(2-ethylhexyl) } \\
\text { phosphate }\end{array}$ & $78-42-2$ & 434.6 & 9.49 & 0.6 \\
\hline DEHP & $\begin{array}{l}\text { di(2-ethylhexyl) } \\
\text { phosphate }\end{array}$ & $298-07-7$ & 322.4 & 6.07 & 182 \\
\hline TEP & Triethyl phosphate & $78-40-0$ & 182.1545 & 0.8 & $5.00 \mathrm{E}+05$ \\
\hline TTBPP & $\begin{array}{c}\text { tris(p-tert-butylphenyl) } \\
\text { phosphate }\end{array}$ & $78-33-1$ & 494.608 & $10.43^{*}$ & $9.616 \mathrm{E}-07^{*}$ \\
\hline
\end{tabular}




\subsubsection{Qualitative and Quantitative Analytical Determination of OPEs in Biological Matrices}

In the last decade, advancements in analytical technology have resulted in the development of a variety of analytical methods for detecting OP triesters, OP diesters, and other OPE metabolites. Early methods of OP triester quantification relied on gas chromatography-mass spectrometry (GC-MS) to analyze biota samples of muscle and liver as well as human plasma and urine (Evenset et al., 2009; Schindler et al., 2009; Shah et al., 2006). This method of analysis, especially for biota samples, resulted in fairly high limits of detection (LOD), leading to the development of methods using liquid chromatography - tandem mass spectrometry (LC-MS/MS) (Chu et al., 2011; Chu \& Letcher, 2015; Su et al., 2014a; Van den Eede et al., 2013a). The transition to LC-MS/MS is logical given that aqueous samples can be injected directly without the need for analyte transfer into an organic solvent, method limits of quantification (MLOQ) tend to be lower, and that more polar compounds such as OP diesters and other metabolites are able to be detected (Quintana et al., 2008a). Interest in the quantification of OP triesters has increased over the last ten years and new methods have emerged to qualify and quantify OPE metabolites in biological samples (Alves et al., 2017; Bastiaensen et al., 2018; Chu et al., 2011; Chu \& Letcher, 2015; 2018). The method developed by Chu et al. (2011) for quantification of five OP diesters using LC-MS/MS was used to analyze in vitro Phase I metabolism of tris(1,3dichloro-2-propyl) phosphate (TDCIPP) and formation by dealkylation of its diester bis(1,3-dichloro-2-propyl) phosphate (BDCIPP) in Wistar Han rat liver microsomes. LCquadrupole-time-of-flight-MS/MS was used after in vitro incubation of five OPEs with human microsomal and S9 liver fractions to identify metabolites (Van den Eede et al., 
2013a). OP diesters were first quantified in biota tissue samples by Su et al. (2014a) using accelerated solvent extraction, followed by weak anion exchange solid phase extraction and HPLC-MS/MS analysis. Very recently, methods have been developed to detect and quantify OP diesters in human samples including hair, nails, and urine, showing potential methods for monitoring human exposure to OPEs (Alves et al., 2017; Carignan et al., 2017; Kosarac et al., 2016). Analytical procedures are also being developed to detect hydroxylated OPEs, another class of OPE metabolite where knowledge regarding distribution in biota and the environment is extremely limited (Bastiaensen et al., 2018; Chu \& Letcher, 2018). However, human biomonitoring data on hydroxylated OPEs remain scarce as current analytical methods tend to focus on OP diesters and obtaining analytical standards for hydroxylated metabolism is difficult. The recent development of a green method to determine OPEs in airborne particulate matter demonstrates a push for science that is both eco-friendly and effective (Naccarato et al., 2018). The method uses a hydroalcoholic mixture for microwave-assisted extraction, has no clean-up step and detects OPEs bound to particulate matter at sub-ng $/ \mathrm{m}^{3}$ levels.

\subsection{Fate of OPEs}

\subsubsection{Distribution in the Environment}

OPEs, as additives to industrial and consumer products, are not chemically bound, resulting in potential for release into the environment during production, use, or disposal of products containing OPEs (World Health Organization, 1998). Once OPEs are emitted, they can settle in a variety of environmental compartments based on the wide range of physicochemical properties of OPEs Once OPEs are emitted, they can reach remote areas 
by infiltration, deposition, and washout (Andresen et al., 2004; Bacaloni et al., 2008; Schreder \& La Guardia, 2014; Takimoto et al., 1999). Recent global distribution of OPEs in the atmosphere has been assessed using polyurethane foam disk passive air samples, deployed during 2014 in the Global Atmospheric Passive Sampling (GAPS) Network. OPEs were detected at every GAPS site, with $\sum{ }_{18} \mathrm{OPEs}$ ranging from 69 to $7770 \mathrm{pg} / \mathrm{m}^{3}$, tris(2-chloroisopropyl) phosphate (TCIPP), tris(chloroethyl) phosphate (TCEP), triphenyl phosphate (TPHP), and tris(2-butoxyethyl) phosphate (TBOEP) dominating (Rauert et al., 2018). In contrast, mean concentrations of PBDEs were low, with $\sum{ }_{14} \mathrm{PBDEs}$ ranging from 0.097 to $93 \mathrm{pg} / \mathrm{m}^{3}$. It is logical that OPE concentrations are reported on average 1-3 orders of magnitude higher than PBDE concentrations given that some OPEs such as TPHP and TDCIPP are used in products to replace PBDEs which are being phased out via the Stockholm Convention (Salamova et al., 2013; Salamova et al., 2014a; Shoeib et al., 2014; Wong et al., 2018).

Multiple studies have found urban areas to have high atmospheric concentrations of OPEs. Salamova et al. (2013) measured atmospheric concentrations of 12 OPEs in the particle phase for air samples taken from 5 different sites around the Laurentian Great Lakes. Total OPE atmospheric concentrations ranged from 120 to $2,100 \mathrm{pg} / \mathrm{m}^{3}$. Urban sites such as Chicago and Cleveland had higher $\sum \mathrm{OPE}$ concentrations that were predominated by chlorinated OPEs such as TCEP, TCIPP, and TDCIPP ( $\mathrm{OPE}$ ranged from 1,500 to $\left.2,100 \mathrm{pg} / \mathrm{m}^{3}\right)$, whereas nonhalogenated OPEs were dominant at rural sites ( $\sum \mathrm{OPE}$ ranged from 120 to $340 \mathrm{pg} / \mathrm{m}^{3}$ ). Similarly, Clark et al. (2017) found statistically significant differences in $\Sigma \mathrm{OPE}$ atmospheric concentrations in urban, suburban, and industrial sites in Houston and Fabiańska et al., (2019) found total OPE concentrations in ambient air 
particulate are directly related to traffic density in urban centers in Poland, resulting in residential areas and villages having lower OPE exposure. Comparable trends have also been noted in outdoor air and particulate matter from Turkey, Canada, Pakistan, Germany, China, and most recently, Tunisia (Castro-Jiménez \& Sempéré, 2018; Faiz et al., 2018; Kurt-Karakus et al., 2018; Saini et al., 2019; Shoeib et al., 2019; Zhang et al., 2019; Zhou et al., 2017).

In addition to being detected in urban locations that are close to industrial processes, OPEs have been found in air as far away as the Arctic and Antarctic, implying potential for long-range atmospheric transport. Particle phase atmospheric samples from Resolute Bay, Svalbard, the North Atlantic and Canadian Arctic have detected OPEs at levels ranging from $35-343 \mathrm{pg} / \mathrm{m}^{3}$, where chlorinated OPEs are most abundant (Li et al., 2017; McDonough et al., 2018; Salamova et al., 2014a; Sühring et al., 2016). OPEs have also been determined in water $(<\mathrm{DL}$ to $4400 \mathrm{pg} / \mathrm{L})$, ocean sediments $(159$ to $4,658 \mathrm{pg} / \mathrm{g}$ dry weight (dw)), and snow (4,356 to $10,561 \mathrm{pg} / \mathrm{L})$ suggesting long-range transport as a major source pathway to these remote locations (Li et al., 2017; Ma et al., 2017; McDonough et al., 2018). OPE levels are consistently shown to be significantly higher than PBDE levels, which when combined with the knowledge of OPE particle phase lifetimes (3.5 - 14 days) imply that OPEs can persist in the atmosphere and undergo long-range transport (Liu et al., 2014).

Because electronics, textiles, and other consumer products have OPEs added to them, it has been demonstrated that indoor environments tend to have high levels of OPEs. Numerous studies have emerged in recent years demonstrating changing OPE concentrations in house dust in response to the phase out of PBDEs, consistently finding 
that OPE concentrations in dust and air are on the rise (Dodson et al., 2012, 2017; Persson et al., 2018; Stapleton et al., 2009; Wong et al., 2018). TBOEP, TCIPP, TDCIPP, and TPHP are commonly detected at $\mu \mathrm{g} / \mathrm{g}$ levels, some reaching $\mathrm{mg} / \mathrm{g}$ levels, though whether chlorinated or alkylated OPEs dominate is dependent on a variety of factors including furnishings in the room and the use of certain floor polishes (Guo et al., 2019; Liu \& Mabury, 2018; Persson et al., 2018; Rantakokko et al., 2019; Tao et al., 2019). Offices, nail salons, vehicles, and automobile parts shops are frequently shown to have higher OPE levels than residential buildings, due in part to a higher presence of OPE-laden electronics and OPE-containing chemicals (Ali et al., 2016; Cao et al., 2019; Carignan et al., 2013; Christia et al., 2018; Kim et al., 2019; Mendelsohn et al., 2016; Zhou \& Püttmann, 2019). Recent measurements in the soil and indoor dust from a rural village in Nepal demonstrate the pervasiveness of OPEs, as the concentration of $\sum_{8} \mathrm{OPEs}$ measured in soil ranged from 65 to $27,500 \mathrm{ng} / \mathrm{g} \mathrm{dw}$ and $\sum_{8} \mathrm{OPEs}$ in indoor dust ranged from 203 to 240,000 ng/g (Yadav et al., 2018; Yadav et al., 2019). Median concentrations of OPEs indoors are shown to be 1-2 orders of magnitude higher than outdoor air and given that indoor dust serves as a relevant exposure pathway for humans, especially toddlers who ingest greater quantities of dust than adults because of increased hand-to-mouth activity and closer proximity to floors; this raises concerns regarding human exposure to OPEs (He et al., 2019; T. Shoeib et al., 2019; Wong et al., 2018).

The extensive use of OPEs as plasticizers and flame retardants in electronics and common household items presents a prominent point source in the form of electronic waste (e-waste) recycling sites. Studies have reported high OPE concentrations in indoor dust (560 to $70,000 \mathrm{ng} / \mathrm{g})$ and air particulate matter $\left(28.6\right.$ to $\left.72.6 \mu \mathrm{g} / \mathrm{m}^{3}\right)$ in e-waste workshops 
in China (Guo et al., 2019; He et al., 2015; Zheng et al., 2015). OPEs have also been found in outdoor environmental samples surrounding Chinese e-waste recycling facilities including fine particulate matter ( 775 to $\left.13,823 \mathrm{pg} / \mathrm{m}^{3}\right)$, soil (122 to $2,100 \mathrm{ng} / \mathrm{g}$ ), and river sediment $(6,010-2,120,000 \mathrm{ng} / \mathrm{g})$ (Li et al., 2019; T. Wang et al., 2018; Y. Wang et al., 2018). Among the OPEs analyzed, TCIPP and TPHP were the dominating species. For the first time, Ren et al. (2019) studied environmental media surrounding an OPE manufacturing site in Hengshui, China that included sediment, water, surface soils, and tree bark. TCEP, TCIPP and TPHP were the main OPEs detected with $\sum$ OPEs ranging from 340 to $270,000 \mu \mathrm{g} / \mathrm{kg} \mathrm{dw}, 7,100$ to $33,000 \mathrm{ng} / \mathrm{L}$, N.D. to $14,000 \mathrm{ng} / \mathrm{kg} \mathrm{dw}$ and 5,300 to $19,000 \mathrm{ng} / \mathrm{g}$ lipid weight in sediments, water, soil, and tree bark, respectively. Sediments and water surrounding OPE manufacturing and recycling plants in Hengshui, and Guiyu contained some of the highest TCIPP, TCEP, and TPHP concentrations reported in the world to date (Li et al., 2019; Ren et al., 2019). These data suggest that e-waste recycling activities are important sources of OPEs to the environment.

In addition to e-waste recycling facilities, wastewater treatment plants (WWTPs) are an area of concern regarding OPEs. OPEs have been reported in WWTP influents, effluents, and sewage sludge in the United States, China, Europe, Australia, and Canada (Hao et al., 2018; Lettieri et al., 2013; O’Brien et al., 2015; Pang et al., 2016; Wang et al., 2019). TBOEP, TCEP, TCIPP and TNBP are the most frequent and abundant OPEs reported in influent and effluent from WWTPs. Chlorinated OPEs are routinely detected in effluent, indicating difficulty removing them during the treatment process, while some alkylated OPEs like TBOEP, show an affinity to sludge (Lettieri et al., 2013; Quintana et al., 2008b; Tang et al., 2019). Primary sources for OPEs entering WWTPs may include 
road run-off and laundry wastewater as a result of household dust accumulating on textiles and transferring to laundry water (Fabiańska et al., 2019; Saini et al., 2016; Schreder \& La Guardia, 2014).

As OPE presence in wastewater effluent has been demonstrated, it is not surprising that OPE levels are a common contaminant found in aquatic environments throughout the world. As with WWTPs, the most frequently detected OPEs in surface water are TBOEP, TCEP, TCIPP, and TNBP (Pantelaki \& Voutsa, 2019). Concentrations in surface water have a wide range that is dependent on urban and industrial activities in their catchment area. Remote areas such as the Fram Strait in the Arctic had concentrations of chlorinated OPEs ranging from $<\mathrm{DL}$ to $4,400 \mathrm{pg} / \mathrm{L}$ and rural portions of the Yangtze River in China had total OPE concentrations range from 24.5 to $68.0 \mathrm{ng} / \mathrm{L}$ (He et al., 2019; McDonough et al., 2018). Water sources in urban and highly industrialized areas such as Beijing and Seoul have higher levels of OPEs (3.24 to $10,945 \mathrm{ng} / \mathrm{L}$ and 28.3 to $16,000 \mathrm{ng} / \mathrm{L}$, respectively) with TCIPP and TCEP consistently being present at highest concentrations (TCIPP mean values $291 \mathrm{ng} / \mathrm{L}$ and $211 \mathrm{ng} / \mathrm{L}$; TCEP mean values $219 \mathrm{ng} / \mathrm{L}$ and $255 \mathrm{ng} / \mathrm{L}$, respectively) (Lee et al., 2018; Shi et al., 2016).

\subsubsection{Distribution in Biota}

Despite a considerable number of studies that have examined OPE levels in abiotic compartments, knowledge on OPE concentrations in biota remains scant and almost entirely focuses on OPE triesters rather than diesters and other metabolites. Additionally OPE levels in air, water and sediment throughout the world are high while OPE levels in biota are very low or non-detectable. Total OPE concentrations in biota (including in fish) 
range from sub ng/g lipid weight (lw) to $1,000 \mathrm{~s} \mathrm{ng} / \mathrm{g}$ lw, with the most frequently detected OPEs being tris(2-ethylhexyl) phosphate (TEHP), TBOEP, TCIPP, TCEP, and TPHP (Greaves et al., 2016a; McGoldrick et al., 2014; Sundkvist et al., 2010). Avian studies have reported OPEs at low or non-detectable levels in a variety of species including peregrine falcon nestlings (Falco peregrinus), white-tailed sea eagle nestlings (Haliaeetus albicilla), kittiwake (Rissa tridactyla), common eider (Somateria mollissima), herring gull (Larus argentatus), cinereous vulture (Aegypius monachus), glaucous gull (Larus hyperboreous), and European starlings (Sturnus vulgaris) (Eulaers et al., 2014; Evenset et al., 2009; Fernie et al., 2017; Greaves et al., 2016a; Lu et al., 2017; Monclús et al., 2018; Stubbings et al., 2018; Su et al., 2015a; Verreault et al., 2018). Moreover, OP diesters and parent triesters have been analyzed in bald eagle (Halieetus leucocephalus) and herring gull eggs (Stubbings et al., 2018; Su et al., 2014b). Reported diester concentrations varied, indicating metabolic rate depends on the structure of the OP triester.

In addition to birds, a large proportion of studies addressing OPE concentrations in biota are focused on fish. Multiple food web studies throughout the world consistently find low to moderate levels of OPEs in fish with low bioaccumulation and no biomagnification potential as well as higher OPE concentrations in benthic fish versus pelagic fish (Brandsma et al., 2015; Greaves et al., 2016a; Hou et al., 2017; Kim et al., 2011; Zhao et al., 2018). Hou et al. (2017) collected topmouth gudgeon (Pseudorasbora parva), crucian carp (Carassius carassius), and loach (Misgurnus anguillicaudatus) samples from urban water sources in Beijing to measure OP triesters and their paired diesters. In whole-body homogenates, $\sum$ OPEs ranged from 264.7 to $1,973 \mathrm{ng} / \mathrm{g}$ lw while $\sum \mathrm{OP}$ diesters ranged from 35.3 to $540 \mathrm{ng} / \mathrm{g}$ lw. Metabolite/parent ratios were calculated, of which BBOEP/TBOEP 
was the highest. Comparable OPE concentrations have also been reported in multiple species of fish from Manila Bay in the Philippines and the Pearl River Delta in southern China (Kim et al., 2011; Ma et al., 2013). Furthermore, in an analysis of OPEs in the Lake Erie and Lake Ontario food web TBOEP was the only quantifiable OPE in lake trout (Salvelinus namaycush) (1.34 ng/g ww mean concentration), walleye (Sander vitreus) (3.17 ng/g ww), and several prey fish including rainbow smelt (Osmerus mordax) (2.64 ng/g ww), and slimy sculpin (Cottus cognatus) (3.52 ng/g ww) (Greaves et al., 2016a). Mysis and plankton samples contained TPHP, TDCIPP, and TNBP, though these samples commonly contain more water than fish samples. It has been shown that bioaccumulation of OPEs in aquatic organisms is controlled both by their hydrophobicity as well as exposure pathways and accumulation mechanisms of the individual organism (Wang et al., 2019). This complexity, compounded with a dearth of knowledge on fate and biotransformation of OPEs, highlights the need for further study regarding toxicokinetics in aquatic biota.

The past two years have seen an increase in studies reporting OP triesters and diesters in humans, especially in children due to concerns regarding higher exposure from increased hand-to-mouth activity. Though OPEs have not been detected in blood samples, TNBP (10 to $57 \mathrm{ng} / \mathrm{g} \mathrm{lw}$ ) and TCIPP (22 to $82 \mathrm{ng} / \mathrm{g} \mathrm{lw}$ ) were detected in breast milk samples from Sweden (Qiao et al., 2016; Sundkvist et al., 2010). Comparatively, breast milk samples from Japan ( $\sum$ OPEs ranged 0.32 to $177 \mathrm{ng} / \mathrm{g}$ lw), the Philippines ( $\sum$ OPEs ranged 11 to $600 \mathrm{ng} / \mathrm{g} \mathrm{lw}$ ), and Vietnam ( $\sum$ OPEs ranged n.d. to $48 \mathrm{ng} / \mathrm{g} \mathrm{lw}$ ) were dominated by TCEP and TPHP. OPE metabolites are increasingly used as exposure biomarkers and have been detected in hair, nail, and urine samples from people living around the world (Guo et al., 2012; Hoffman et al., 2017a; Ospina et al., 2018; Qiao et al., 2016; Zhang et 
al., 2018).

\subsection{Absorption, Distribution, Metabolism, and Excretion (ADME)}

\subsubsection{Absorption, Distribution, Excretion}

General information on the absorption, distribution, and excretion of OPEs in the body is sparse. Multiple routes of exposure have been identified including inhalation, dust ingestion, dermal absorption, and dietary intake (Abou-Elwafa Abdallah et al., 2016; Bello et al., 2018; Cequier et al., 2015; He et al., 2018; Schreder et al., 2016). There is additional concern regarding chronic occupational exposure to compounds containing OPEs given the lack of knowledge on transformation and chronic toxicity of OPEs in humans (Bello et al., 2018; Hoffman et al., 2017a). Zebrafish (Danio rerio) exposed to environmentally relevant concentrations of deuterated TPHP $\left(\mathrm{d}_{15}\right.$-TPHP) for 19 days resulted in some interesting partitioning (Wang et al., 2016). The intestine contained the highest $\mathrm{d}_{15}$-TPHP concentration ( $3.12 \pm 0.43 \mu \mathrm{g} / \mathrm{g} \mathrm{ww})$ followed by the gills $(2.76 \pm 0.12 \mu \mathrm{g} / \mathrm{g} \mathrm{ww})$, brain ( $2.58 \pm 0.19 \mu \mathrm{g} / \mathrm{g} \mathrm{ww})$, liver $(2.30 \pm 0.34 \mu \mathrm{g} / \mathrm{g} \mathrm{ww})$, and muscle $(0.53 \pm 0.04 \mu \mathrm{g} / \mathrm{g} \mathrm{ww})$. Seven metabolites were identified, with $\mathrm{d}_{10}$-DPHP detected in the liver and intestine up to $3.0-3.5$ times higher than concentrations of $\mathrm{d}_{15}$-TPHP. The gills and intestine accumulated more TPHP than what was predicted based on lipid contents, likely due to accumulating TPHP from direct contact with suspended particles. Also, $\mathrm{d}_{15}$-TPHP was detected in the brain but metabolites were not, indicating TPHP could cross the blood-brain barrier but metabolites may be rapidly conjugated with sulfate, glucuronide, or glutathione and thus not be present in the brain. This study was then expanded to include TCEP, tripropyl phosphate (TPP), TNBP, TBOEP, TCIPP, tri-p-cresyl phosphate (TCP), finding that 
bioaccumulation of OPEs varied among tissues (Wang et al., 2017). The lowest concentrations of OPEs were in the muscle and the highest concentrations for TPP and TCEP were in the liver. High levels of TDCIPP, TPHP, and TCP were observed in roe, indicating a potential for OPE transfer to offspring. Biotransformation of OPEs with aryl moieties (TCP \& TPHP) and polychlorinated alkyl moieties (TDCIPP) has more significant impacts on accumulation than OPEs with short chain alkyl moieties. Diester metabolites BDCIPP and DPHP were found approximately 1.2 and 2.0 times higher than parent OPEs in the liver and were also detected in the water at levels $1 / 3$ to $1 / 4$ that of parent OPEs. While the partition process between tissues and blood was the dominant process for OPE accumulation, biotransformation was another important factor affecting the accumulation of some OPEs. The distribution of OPEs in the intestine and liver imply the hepatobiliary system (liver-bile-intestine) is a relevant compartment for the metabolism and excretion of OPEs in zebrafish (Wang et al., 2017).

\subsubsection{Metabolism}

As with biomonitoring studies, the number of in vitro and in vivo OPE metabolism studies has increased in recent years, though it still remains limited. Early metabolism studies in rat liver microsomes generally found that OPEs undergo rapid metabolism with TNBP metabolized the fastest followed by TPHP, then TDCIPP, and TCEP showed minimal degradation (Sasaki et al., 1984). Since the 1980s, no published literature could be found on the metabolism of OPEs until this decade. More recently, herring gull liver microsomes were found to metabolize a suite of OPEs in the following order: TNBP > TBOEP $>$ TCIPP $>$ TPHP $>$ TDCIPP, with no degradation of triethyl phosphate (TEP) 
(Greaves et al., 2016b). The $V_{\operatorname{MAX}}$ (reaction rate when the enzyme system is fully saturated) varied for each OPE, though all were $1-2$ orders of magnitude less than $\mathrm{V}_{\text {MAX }}$ values for TCIPP metabolized in human liver microsomes $(1,470 \pm 110 \mathrm{pmol} / \mathrm{min} / \mathrm{mg}$ protein) as well as TBOEP and TNBP metabolized in crucian carp liver microsomes $(462.9 \pm 56.8$ $\mathrm{pmol} / \mathrm{min} / \mathrm{mg}$ protein and $586.9 \pm 179.5 \mathrm{pmol} / \mathrm{min} / \mathrm{mg}$ protein, respectively) (Greaves et al., 2016b; Hou et al., 2018; Van den Eede et al., 2015, 2016a). The variation among these studies suggest that hepatic metabolism rates are both structure - dependent and vary among different species.

Mass balance is important to consider when determining OP triester depletion. In ringed seal (Pusa hispida), polar bear (Ursus maritimus), and herring gull microsomes diester formation for TEHP, TNBP, and TBOEP did not account for $100 \%$ of parent triester depletion, nor was TDCIPP completely converted to BDCIPP during an in ovo metabolism study in Japanese quail (Coturnix japonica) suggesting that there are additional pathways responsible for OPE metabolism (Briels et al., 2018; Strobel et al., 2018a; Greaves et al., 2016b). Other studies have identified a variety of OPE Phase I and Phase II metabolites including OP diesters, hydroxylated OP triesters, hydroxylated OP diesters, and glucuronic acid conjugated metabolites that form after hydroxylation (Wang et al., 2017). Su et al. (2014a) used chicken embryonic hepatocytes to show that $0.2 \%$ of the initial concentration of TPHP remained after 36 hours, where DPHP accounted for only $17 \%$ of TPHP metabolized. A subsequent study determined Phase I hydroxylation and Phase II conjugation metabolic pathways were just as relevant as diester formation when para-OHTPHP accounted for $60 \%$ of TPHP dosed, which is primarily conjugated with glucuronic acid (Su et al., 2015b). Hydroxylated metabolites were also identified for TNBP in rat liver 
microsomes as TNBP-OH, which was further metabolized to TNBP- $(\mathrm{OH})_{2}$ and DNBP (Sasaki et al., 1984). In human liver S9 fraction and microsomes, metabolites of TDCIPP, TCIPP, TCEP, and TPHP were examined. BDCIPP and DPHP were major metabolites of TDCIPP and TPHP, respectively, whereas TCIPP was found to undergo oxidative dehalogenation and TCEP metabolism to bis(2-chloroethyl) phosphate (BCEP) was minimal (Van den Eede et al., 2013a). While the metabolism pathways of OPEs are demonstrably complex, a very limited number of studies have shown that regarding $O$ dealkylation, diesters are the final degradation product with no monoester formation (Sasaki et al., 1984; Su et al., 2016a; Wang et al., 2017).

The formation of hydroxylated metabolites indicates cytochrome P450 enzymes (CYPs) are mediating the metabolism of OP triesters (Van den Eede et al., 2015). In human liver microsomal studies, glucuronyl transferases (UGTs) or sulfotransferases (SULTs) likely facilitate further transformation to glucuronic acid or sulfuric acid conjugates (Van den Eede et al., 2013a). Beyond CYP enzymes that are dependent on nicotinamide adenine dinucleotide phosphate (NADPH) as a coenzyme, other NADPH - independent enzymes are likely involved in OP metabolism given that in experiments lacking an NADPH regenerating system, TPHP was still degraded to DPHP in human, Wistar Han rat, and polar bear liver microsomes (Sasaki et al., 1984; Strobel et al., 2018a; Van den Eede et al., 2013a). Suggested NADPH - independent enzymes include aryl esterases and paraoxonases (Van den Eede et al., 2015; Van den Eede et al., 2013a). Hou et al. (2018) recently reported in vitro metabolism of TNBP and TBOEP in crucian carp, using inhibition studies to identify specific CYP450 isozymes involved in metabolism of alkyl OPEs. CYP3A4 and CYP1A were suggested as significant contributors to the metabolism 
of TNBP and TBOEP, however knowledge of which Phase I and Phase II isoenzymes catalyzing the metabolism of OPEs in any species is nearly nonexistent as there is little to no data available in the current literature. Metabolism of OPEs as a class of compounds in fish may be more complex and is poorly understood.

\subsection{Adverse Effects of OPEs}

The growing prevalence of OPEs in the environment increases the urgency to assess the risk of OPEs to organisms. This class of compounds is diverse and toxicological studies indicate that transformation and fate are structure-dependent. A variety of studies have reported toxicological effects after exposure to OPEs at environmentally relevant concentrations. For example, zebrafish have been used to demonstrate cardiotoxicity of TPHP, a decrease in fecundity caused by TDCIPP and TPHP, and the ability for TDCIPP to be transferred to offspring, resulting in developmental neurotoxicity (Du et al., 2015; Liu et al., 2013; Wang et al., 2015; Yu et al., 2017; Zhang et al., 2018a; Zhang et al., 2018b). Additional adverse effects of OPE exposure include developmental toxicity (Dasgupta et al., 2018; Dasgupta et al., 2017; Jacobsen et al., 2017; Li et al., 2018; Oliveri et al., 2018; Wang et al., 2019; Yan \& Hales, 2018), oxidative stress (Chen et al., 2015a; Chen et al., 2015b; Gu et al., 2019; Lu et al., 2017; Yan et al., 2017), thyroid disruption (Fernie et al., 2017; Hill et al., 2018; Liu et al., 2019; Preston et al., 2017), neurotoxicity (Andresen et al., 2004; Hong et al., 2018; Li et al., 2019; Shi et al., 2018; Slotkin et al., 2017), carcinogenicity (Hoffman et al., 2017b; Ni et al., 2007; Van den Eede et al., 2013b), endocrine disruption (Arukwe et al., 2016; Chen et al., 2015; Kojima et al., 2013; Kojima et al., 2016; Wang et al., 2015), and cellular toxicity (Shen et al., 2019; Canbaz et al., 2017; Crump et al., 2012; Shen et al., 2019; Su et al., 2014a). Additionally, non-human LD50 
values are listed in Table 1.2. Adverse effects of OP metabolites are much less characterized. Su, et al. (2014a) found DPHP was less cytotoxic than its parent triester TPHP but altered more transcripts in chicken embryonic hepatocytes. In 3T3-L1 cells, DPHP enhanced lipolysis and acted as an endocrine disruptor on the regulation of adipogenic differentiation (Cano-Sancho et al., 2017). Bis(2-butoxyethyl) hydroxyethyl phosphate (BBOEHEP) and 3-OH-TBOEP have been shown to act as pregnane $\mathrm{X}$ receptor agonists, similar to their parent compound TBOEP as well as TEHP, and TNBP (Kojima et al., 2016). Metabolism can significantly influence the accumulation and adverse effects of chemicals in organisms, however the transformation of OPEs and distribution of their metabolites are still unknown. The aim of this project is to shed light on this issue with regard to aquatic environments by investigating OPE metabolism in fish using a variety of structurally diverse compounds to provide data for future elucidation of toxic effects. 
Table 1.2 LD50 of selected OPEs in recent reports. LD50 values are unavailable for TTBPP, DPHP, DNBP, BBOEP, BDCIPP, and DEHP. All values are from PubChem.

\begin{tabular}{|c|c|c|c|}
\hline Compound & Species & Administration route & LD50 (mg/kg bw) \\
\hline \multirow[t]{6}{*}{ TPHP } & Mouse & Oral & 1320 \\
\hline & Rat & Oral & 3800 \\
\hline & Chicken & Oral & $>5000$ \\
\hline & Rabbit & Dermal & $>7900$ \\
\hline & Cat & Subcutaneous & 100 \\
\hline & Guinea pig & Oral & $>4000$ \\
\hline \multirow[t]{8}{*}{ TNBP } & Mouse & Intraperitoneal & $100-200$ \\
\hline & Rat & Intraperitoneal & 251.2 \\
\hline & Guinea pig & Dermal & $9700-19,400$ \\
\hline & Rabbit & Dermal & $>10,000$ \\
\hline & Rat & Inhalation & $\mathrm{LC} 50:>4.242 \mathrm{mg} / \mathrm{L} 4 \mathrm{hr}$ \\
\hline & Hen & Oral & 1500 \\
\hline & Mouse & Oral & 900 \\
\hline & Rat & Oral & 11,265 \\
\hline \multirow[t]{3}{*}{ TBOEP } & Rat & Oral & 3000 \\
\hline & Mouse & Intravenous & 180 \\
\hline & Guinea pig & Oral & 3000 \\
\hline \multirow[t]{3}{*}{ TDCIPP } & Rat & Dermal & $>2000$ \\
\hline & Rat & Oral & $1898-2933$ \\
\hline & Mouse & Oral & 2250 \\
\hline \multirow[t]{2}{*}{ TEHP } & Rat & Oral & $>36,800$ \\
\hline & Rabbit & Oral & 46,000 \\
\hline \multirow[t]{6}{*}{ TEP } & Rat & Oral & 1600 \\
\hline & Rat & Intraperitoneal & 800 \\
\hline & Rabbit & Oral & 1600 \\
\hline & Rabbit & Intraperitoneal & 800 \\
\hline & Mouse & Oral & $>1500$ \\
\hline & Mouse & Intraperitoneal & 485 \\
\hline
\end{tabular}




\subsection{Thesis Objectives and Hypotheses}

Due to the ubiquitous presence of OPEs worldwide, concerns are mounting regarding the toxicokinetics (ADME) and, in particular, the transformation process and influence on bioaccumulation and biomagnification potential of OPEs in aquatic food webs. The production and use of flame retardant POPs such as PBDEs and HBCDD has been globally regulated since they have been listed in 2009 and 2013, respectively, under Annex A of the Stockholm Convention. As a consequence, OPEs have seen a significant increase in production and use; however, current research indicates OPEs may not be a suitable replacement for PBDEs from a toxicological standpoint. This project aims to understand the influence of metabolism on the fate of seven diverse, environmentally relevant triester OPEs (Figure 1.2) and provide degradation and respective metabolite formation insights in an aquatic predatory species, rainbow trout (Oncorhynchus mykiss). It is hypothesized that rainbow trout are comparatively different than birds and mammals in their ability to metabolically deplete OP triesters and form OP diesters given that they are ectotherms. Furthermore, OP triester metabolic depletion and diester formation in rainbow trout are hypothesized to be a function of OPE structure. To test these hypotheses, the OPEs chosen for this project are environmentally relevant and are listed as a priority substance for risk assessment under the Government of Canada's Chemicals Management Plan.

The following major research questions address the objectives and hypotheses of this thesis:

1. How does OPE structure affect rate of OP triester depletion and OP diester formation in an in vitro rainbow trout liver microsomal system? 
2. What cross-taxa comparisons can be made regarding OPE metabolism in the present fish model study compared to results reported for model human, avian and mammalian in vitro studies? 
<smiles>CCCCCOP(=O)(OCCCC)OCCCC</smiles>

TNBP<smiles>CCCCOP(=O)(O)OCCCC</smiles>

DNBP<smiles>CCCCC(CC)COP(=O)(OCC(CC)CCCC)OCC(CC)CCCC</smiles>

TEHP

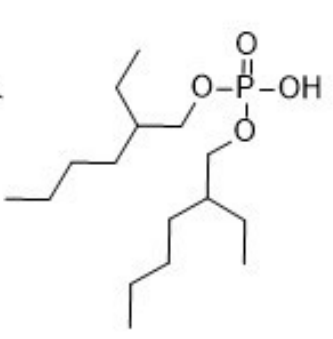

DEHP<smiles>O=P(OC(CCl)CCl)(OC(CCl)CCl)OC(CCl)CCl</smiles>

TDCIPP<smiles>CC(C)(C)c1ccc(OP(=O)(Oc2ccc(C(C)(C)C)cc2)Oc2ccc(C(C)(C)C)cc2)cc1</smiles><smiles>O=P(O)(OC(CCl)CCl)OC(CCl)CCl</smiles>

BDCIPP
TBOEP

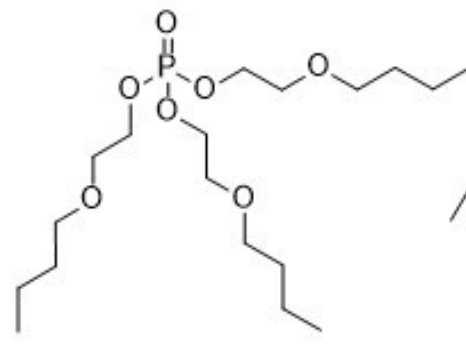

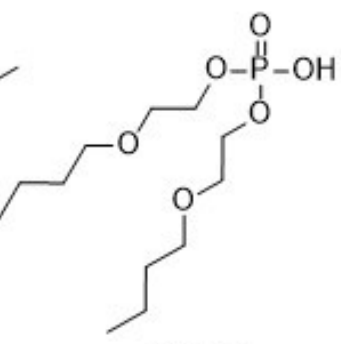

BBOEP<smiles>O=P(Oc1ccccc1)(Oc1ccccc1)Oc1ccccc1</smiles>

TPHP<smiles>O=P(Oc1ccccc1)(Oc1ccccc1)Oc1ccccc1</smiles>

DPHP

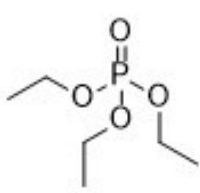

TEP

Figure 1.2 Chemical structures of all target organophosphate triesters and diesters in this thesis. Full compound names, CAS identification numbers, molecular mass, $\log \mathrm{K}_{o w}$, and water solubility can be found in Table 1.1. Hydrogen atoms have been omitted for clarity. 


\section{Chapter 2: Materials and Methods}

\subsection{Chemicals and Reagents}

Unless specified otherwise, all purchased standards had a chemical purity ranging between 94 and 99.8\%. The following OP triester and diester standards were purchased from Sigma-Aldrich (Oakville, ON, Canada): TDCIPP, TBOEP, TPHP, TNBP, TEP, TEHP, TTBPP (purity unknown), DNBP, and DEHP. Mass-labelled internal standards $\mathrm{d}_{15^{-}}$ TDCIPP, $\mathrm{d}_{15}$-TPHP, $\mathrm{d}_{10}$-BDCIPP, $\mathrm{d}_{10}$-DPHP, and $\mathrm{d}_{4}$-BBOEP as well as OP diesters BDCIPP and BBOEP were obtained from Dr. Belov at the Max Planck Institute for Biophysical Chemistry (Germany). $\mathrm{d}_{27}{ }^{-}$TNBP was purchased from Cambridge Isotope Laboratories (Andover, MA, USA) and $\mathrm{d}_{33}$-T4IPPP ( $>97 \%$ purity) was purchased from Caledon (Georgetown, ON, Canada). All standards were prepared to concentration in methanol. Rainbow trout microsomes (20 mg microsomal protein $/ \mathrm{mL}$ ) were obtained from ThermoFisher Scientific (Waltham, MA, USA). NADPH regenerating system solution A and NADPH regenerating system solution B were purchased from VWR (Radnor, PA, USA). Potassium phosphate buffer, $\mathrm{pH}$ 7.4, was purchased from Alfa Aesar (Ward Hill, MA, USA).

\subsection{In Vitro Biotransformation Assay for OPEs}

Due to the widespread presence of OPEs in plastic materials, glass materials were used wherever possible. Glassware was heated to $450^{\circ} \mathrm{C}$ for 8 hours prior to use. All in vitro biotransformation assays followed previously published methods for rat, herring gull, polar bear, and ringed seal liver microsomes (Chu et al., 2011; Chu \& Letcher, 2015; Greaves et al., 2016b; Strobel et al., 2018a; Strobel et al., 2018b). In brief, liver microsomes 
and NADPH regenerating solutions $\mathrm{A}$ and $\mathrm{B}$ were thawed on ice while the OP triester dosing solution (see Figure 1.2 for names, structures, and physicochemical properties of selected OPEs) was brought to room temperature. Potassium phosphate buffer $(0.5 \mathrm{M}, 7.4$ $\mathrm{pH}$ ) was spiked with $3 \mu \mathrm{L}$ OP triester dosing solution (final concentration $2 \mu \mathrm{M}$ ) along with $50 \mu \mathrm{L}$ of NADPH regenerating solution $\mathrm{A}, 10 \mu \mathrm{L}$ of NADPH regenerating solution B and $50 \mu \mathrm{L}$ of microsomes $(20 \mathrm{mg}$ microsomal protein $/ \mathrm{mL}$ ) for a final reaction mixture volume of $1 \mathrm{~mL}$. The $2 \mu \mathrm{M}$ OPE dose was chosen based on Greaves et al. (2016b) where it was determined that $2 \mu \mathrm{M}$ was $\gg 2 \times K_{M}$ to ensure a zero-order metabolic reaction was achieved and the metabolic enzyme system was saturated. One minor modification to the approach was made regarding the temperature, where instead of incubating the assay solutions in a water bath at $37^{\circ} \mathrm{C}$, the incubation temperature was lowered to $25^{\circ} \mathrm{C}$ to best replicate a piscine environment for the rainbow trout microsomes. The assay solutions were incubated at $25^{\circ} \mathrm{C}$ for 2 minutes with a shaker set to move horizontally $2.4 \mathrm{~cm}$ for 176 times per minute (80 RPM) prior to adding $50 \mu \mathrm{L}$ of microsomes and vortexing thoroughly. Aliquots of $100 \mu \mathrm{L}$ were removed from the reaction mixture at designated time intervals $(0,1,2,5,10,40,70$, and 100 minutes $)$ and added to $400 \mu \mathrm{L}$ of methanol containing internal standards (25 ppb each) to quench the reaction and terminate enzymatic activity. The solutions were capped to prevent evaporation until they were microcentrifugated in prewashed tubes with a microcentrifugal filter (nylon $0.2 \mu \mathrm{m}$ pore size, $500 \mu \mathrm{L}$ capacity; VWR, Mississauga, ON, Canada) in an Eppendorf Mini Spin Plus with an F-45-12-11 rotor at $10,000 \mathrm{RPM}(6708 \times \mathrm{g})$ for 5 minutes. The solutions were then transferred to UPLC vials and stored at $4^{\circ} \mathrm{C}$ for analysis with the exception of TTBPP which had an additional 
dilution step to ensure the samples stayed within the linear analytical response range. Each TTBPP sample was diluted at a ratio of 1:1 with $100 \mu \mathrm{L}$ of sample and $100 \mu \mathrm{L}$ of methanol.

\subsection{Quality Assurance and Control}

For every OPE triester tested, 2 inter-day assays were performed in triplicate. The following controls were run with every batch of samples: a methanol blank, a negative control, and a positive control. The methanol blank contained all the reagents used in the samples except for the OP triester of interest which was replaced with $3 \mu \mathrm{L}$ of methanol. It was consistently shown not to contain quantifiable levels of OPEs studied. Negative controls used deactivated rainbow trout liver microsomes that had been denatured at $100^{\circ} \mathrm{C}$ for 5 minutes and were otherwise treated identically to triplicate samples. This showed that in the absence of enzymatically viable microsomes, OP triesters were not degraded. Because of the temperature change from Chu et al. 2011, positive controls were conducted with rainbow trout microsomes instead of Wistar Han rat microsomes. Since complete metabolism was demonstrated for TBOEP in rainbow trout microsomes and not TDCIPP, TBOEP was used in every positive control, consistently showing complete depletion of TBOEP. A seven-point linear calibration curve was run with each batch $\left(\mathrm{r}^{2}\right.$ was consistently well above 0.90 ). Known quantities of internal standards were used to accurately compare unknown OP triester and diester concentrations.

\subsection{Determination of OP Triester Depletion and OP Diester Formation}

All in vitro biotransformation assay samples were analyzed for OP triesters and their respective diesters using a Waters Acquity ultra-high performance liquid 
chromatography (UPLC) coupled to a Waters Xevo TQ-S triple quadrupole mass spectrometer operated in the electron spray ionization $(\operatorname{ESI}(+))$ mode. Target compounds were then separated using a Waters Acquity UPLC BEH $\mathrm{C}_{18}$ column $(50 \mathrm{~mm} \mathrm{~L} \mathrm{x} 2.1 \mathrm{~mm}$ i.d., $1.7 \mu \mathrm{m}$ particle size) (Chu et al., 2011). The mobile phase consisted of water (A) and methanol (B) each containing $2 \mathrm{mM}$ ammonium acetate. The column temperature was set to $40^{\circ} \mathrm{C}$, the samples were maintained at $20^{\circ} \mathrm{C}$ and the injection volume was $5 \mu \mathrm{L}$. The mobile phase flow rate was set to $0.5 \mathrm{~mL} / \mathrm{min}$ and the following gradient was applied: $5 \%$ $\mathrm{B}$ ramped to $95 \% \mathrm{~B}$ over 5 minutes (linear), held for 1 minute, dropped to $5 \% \mathrm{~B}$ and held for 4 minutes, for a total run time of 10 minutes. $0.1 \mathrm{mM}$ decamethonium hydroxide (a dicationic reagent) was mixed with the mobile phase post LC separation with a "T" connector at a flow rate of $10 \mu \mathrm{L} / \mathrm{min}$. Instrument operation parameters for ESI $(+)$ were as follows: capillary voltage: $0.5 \mathrm{kV}$; desolvation temperature: $600^{\circ} \mathrm{C}$; desolvation gas flow rate: $800 \mathrm{~L} / \mathrm{hr}$; cone gas flow rate: $150 \mathrm{~L} / \mathrm{hr}$.

Compound identification was based on retention times compared to authentic standards and their characteristic mass transitions observed by multiple reaction monitoring. For every set of samples, a seven-point calibration curve was performed to ensure linearity of response and to allow for quantification. Quantification was accomplished with MassLynx (Waters, 2014) and additional details regarding UPLC analysis, including all monitored transitions can be found in Table 2.1.

\subsubsection{Determination of TTBPP Depletion}

Quantification of TTBPP (Figure 1.2) depletion and formation of the diester DPHP was conducted using a Waters Acquity ultra-high performance liquid chromatography 
(UPLC) coupled to a Waters Xevo TQ-S triple quadrupole mass spectrometer operated in the electron spray ionization $(\operatorname{ESI}(+))$ mode. Target compounds were then separated using a Waters Acquity UPLC BEH $\mathrm{C}_{18}$ column $(50 \mathrm{~mm} \mathrm{~L} \mathrm{x} 2.1 \mathrm{~mm}$ i.d., $1.7 \mu \mathrm{m}$ particle size) (Chu et al., 2011). The mobile phase consisted of water (A) and methanol (B) each containing $2 \mathrm{mM}$ ammonium acetate. The column temperature was set to $40^{\circ} \mathrm{C}$, the samples were maintained at $20^{\circ} \mathrm{C}$ and the injection volume was $10 \mu \mathrm{L}$. The instrument operation parameters for ESI $(+)$ were as follows: capillary voltage: $1.0 \mathrm{kV}$; desolvation temperature: $600^{\circ} \mathrm{C}$; source temperature: $150^{\circ} \mathrm{C}$; desolvation gas flow rate: $800 \mathrm{~L} / \mathrm{hr}$; cone gas flow rate: $150 \mathrm{~L} / \mathrm{hr}$. The mobile phase flow rate was set to $0.5 \mathrm{~mL} / \mathrm{min}$ and the following gradient was applied: 5\% B ramped to 95\% B over 5 minutes, held for 2 minutes, dropped to 5\% B and held for 5 minutes, for a total run time of 12 minutes.

Compound identification was based on retention times compared to authentic standards and their characteristic mass transitions observed by multiple reaction monitoring. For every set of samples, a seven-point calibration curve was performed to ensure linearity of response and to allow for quantification. Quantification was accomplished with MassLynx (Waters, 2014) and additional details regarding UPLC analysis, including all monitored transitions can be found in Table 2.1.

\subsection{Data Analysis}

All statistical analysis was done using Prism Version 8.0c GraphPad (GraphPad Software, San Diego, CA, USA). Analyte concentrations were determined from the UPLC where peaks were automatically integrated and adjusted based on the internal standard concentration. The concentrations were then converted from $\mathrm{ppb}$ to $\mathrm{nmol} / \mathrm{L}$ and adjusted 
to previous dilutions. For TDCIPP, TBOEP, TPHP, TNBP, TEP, and TEHP time-course nonlinear regressions were plotted using the one phase decay or one phase association and least squares fit functions. TTBPP was plotted using a linear regressions and least squares fit function. Shapiro-Wilk and D'Agostino \& Pearson tests were used to determine whether parametric (ANOVA) or non-parametric (Friedman) tests would be used to determine the level of significance at each time point compared to the initial concentration measured at 1 minute and the Brown-Forsythe test was used to test homogeneity of variance. The acceptable level of significance was $p<0.05$. ANOVA was paired with Dunnett's multiple comparisons test and Friedman non-parametric was paired with Dunn's multiple comparisons test. 
Table 2.1. Operating parameters of MS/MS for in vitro analysis including the multiple reaction monitoring (MRM) transitions and mass-labelled internal standards.

\begin{tabular}{|c|c|c|c|c|c|}
\hline Compound & $\begin{array}{l}\text { MRM } \\
\text { Transition }\end{array}$ & Dwell (s) & Cone (V) & $\begin{array}{l}\text { Collision } \\
(\mathrm{eV})\end{array}$ & $\begin{array}{l}\text { Internal } \\
\text { Standard }\end{array}$ \\
\hline TDCIPP & $430.90>99.00$ & 0.009 & 42 & 26 & $\mathrm{~d}_{15}$-TDCIPP \\
\hline $\mathrm{d}_{15}$-TDCIPP & $446.00>102.00$ & 0.009 & 42 & 26 & $\mathrm{~N} / \mathrm{A}$ \\
\hline BDCIPP & $577.20>243.30$ & 0.009 & 53 & 30 & $\mathrm{~d}_{10}$-BDCIPP \\
\hline $\mathrm{d}_{10}$-BDCIPP & $587.30>243.30$ & 0.009 & 53 & 30 & N/A \\
\hline TBOEP & $399.00>199.00$ & 0.009 & 35 & 15 & $\mathrm{~d}_{15}$-TDCIPP \\
\hline BBOEP & $555.50>243.30$ & 0.009 & 43 & 25 & $\mathrm{~d}_{4}$-BBOEP \\
\hline $\mathrm{d}_{4}$-BBOEP & $559.50>243.30$ & 0.009 & 43 & 25 & N/A \\
\hline ТPHP & $327.10>77.10$ & 0.009 & 100 & 40 & $\mathrm{~d}_{15}$-ТPHP \\
\hline $\mathrm{d}_{15}$-TPHP & $342.20>82.00$ & 0.009 & 100 & 40 & $\mathrm{~N} / \mathrm{A}$ \\
\hline DPHP & $507.30>243.30$ & 0.009 & 42 & 28 & $\mathrm{~d}_{10}$-DPHP \\
\hline $\mathrm{d}_{10}-\mathrm{DPHP}$ & $517.40>243.30$ & 0.009 & 42 & 28 & N/A \\
\hline TNBP & $267.10>99.00$ & 0.009 & 35 & 20 & $\mathrm{~d}_{27}$-TNBP \\
\hline $\mathrm{d}_{27}$-TNBP & $294.30>102.00$ & 0.009 & 35 & 20 & N/A \\
\hline DNBP & $467.40>243.30$ & 0.009 & 0 & 26 & $\mathrm{~d}_{10}$-BDCIPP \\
\hline TEP & $183.00>98.70$ & 0.009 & 35 & 17 & $\mathrm{~d}_{15}$-TDCIPP \\
\hline TEHP & $435.40>99.30$ & 0.164 & 24 & 12 & $\mathrm{~d}_{15}$-TDCIPP \\
\hline DEHP & $579.50>243.30$ & 0.053 & 40 & 28 & $\mathrm{~d}_{4}$-BBOEP \\
\hline ТТВРР & $395.3>439.4$ & 0.029 & 19 & 22 & $\mathrm{~d}_{33}$-T4IPPP \\
\hline $\mathrm{d}_{33}$-T4IPPP & $486.4>342.2$ & 0.029 & 8 & 30 & $\mathrm{~N} / \mathrm{A}$ \\
\hline
\end{tabular}




\section{Chapter 3: Results and Discussion}

\subsection{In vitro OP Triester Metabolism and OP Diester Formation}

To investigate the effects of OPE structure on in vitro metabolism, a suite of seven OPEs were chosen to represent a varied range of structures and physicochemical properties. The selected OPEs have been consistently detected in the environment and to a lesser degree in biota, making them an environmentally relevant choice for study. Additionally, previous in vitro studies with these OPEs in polar bear, ringed seal, herring gull, and crucian carp allow for cross-taxa comparison between avian, mammalian, and piscine models (Greaves et al., 2016b; Hou et al., 2018; Strobel et al., 2018a)

Given the procedural changes from $\mathrm{Chu}$ et al. (2011) to maintain optimal temperature conditions for fish microsomes, TBOEP was used in the positive control instead of TDCIPP for each batch. TBOEP was consistently depleted completely in the positive controls during the 100 minute incubation period. Negative controls were also run with each assay with deactivated rainbow trout microsomes and demonstrated no aqueous depletion. The resulting OP triester depletion and OP diester formation in rainbow trout microsomes occurred at varying degrees, indicating structure - specific metabolic differences in in vitro rainbow trout microsomes (Figure 3.1). Rapid and complete depletion of TBOEP was observed in rainbow trout microsomes whereas TNBP and TEHP showed slow and incomplete depletion. TTBPP showed minimal depletion and TPHP, TDCIPP, and TEP were not depleted. These trends are similar to those reported previously in ringed seal, which used a comparable assay (Strobel et al., 2018a; Strobel et al., 2018b). In general, both ringed seal and rainbow trout microsomes metabolized OPEs less rapidly than herring gull and polar bear microsomes. 
As with previous metabolism studies, non-halogenated OPEs (TBOEP and TNBP) were metabolized more rapidly and completely than OPEs with chlorinated or aryl moieties, with the exception of TEP which showed no depletion across all species studied thus far. Hou et al. (2018) recently characterized in vitro metabolism of TBOEP and TNBP in crucian carp liver microsomes, similarly finding that TBOEP and TNBP were rapidly metabolized during a 200 minute incubation period. Steric hindrance and polarity likely affect metabolism and these results indicate the importance of considering OPEs individually from a toxicity assessment standpoint as there is such variance among even a small grouping of OPEs. 
TDCIPP \& BDCIPP

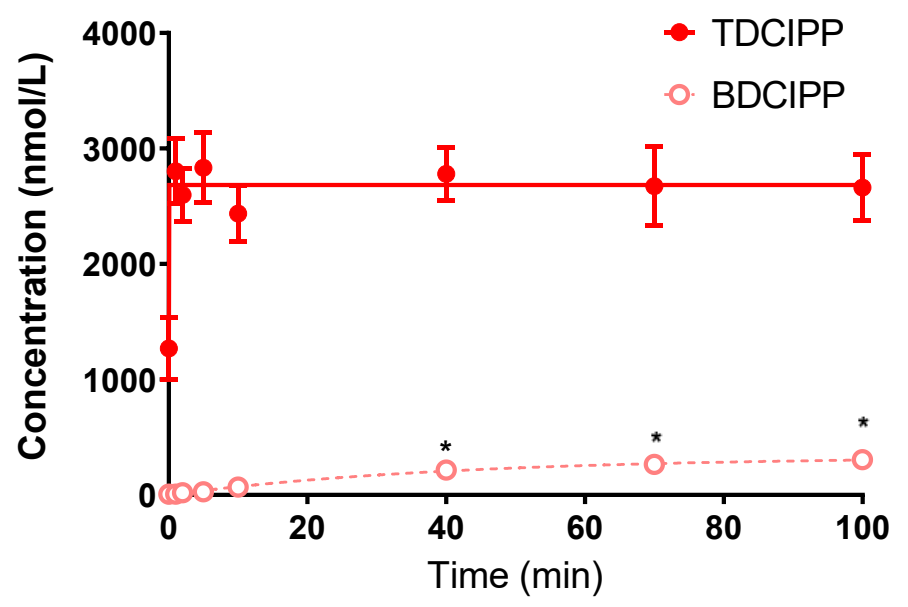

TBOEP \& BBOEP

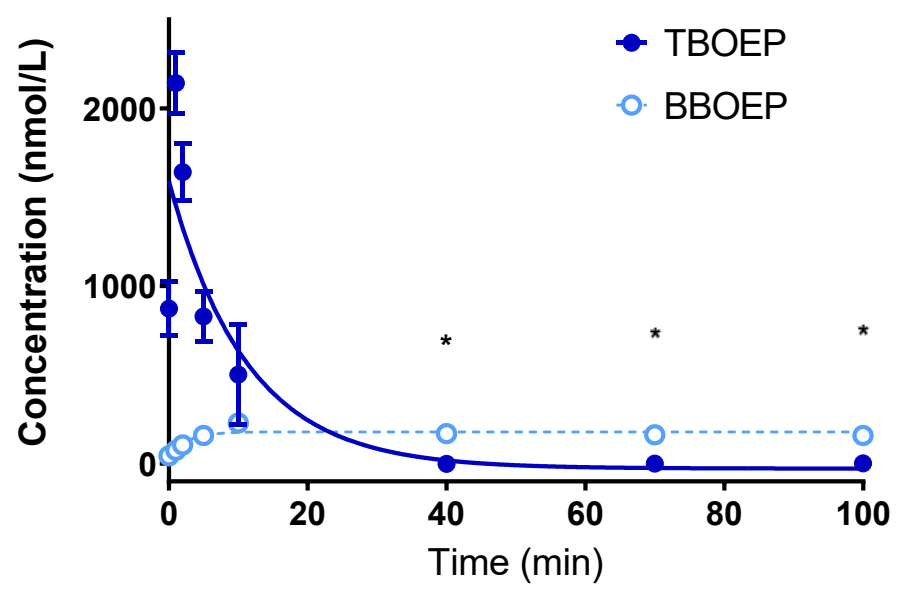

TNBP \& DNBP

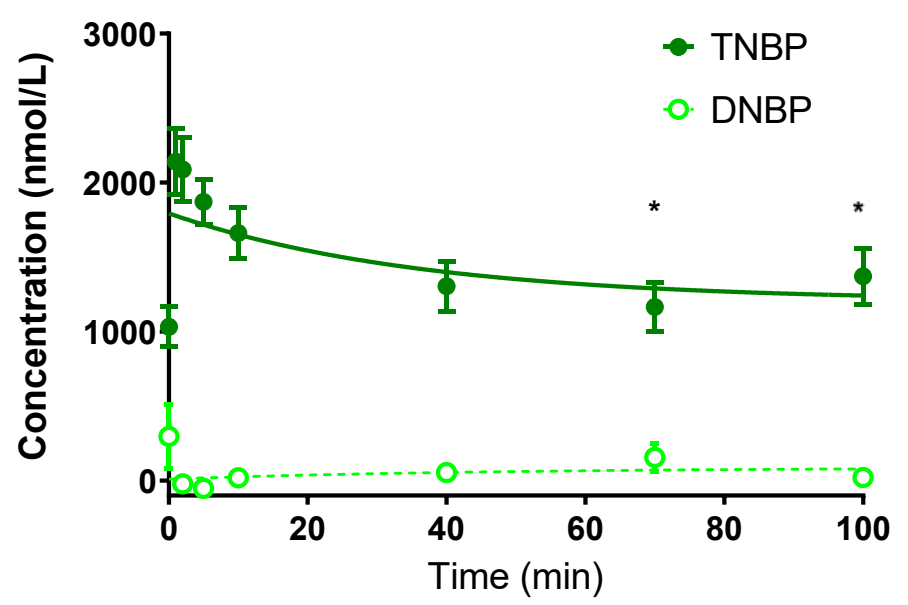




\section{TPHP \& DPHP}

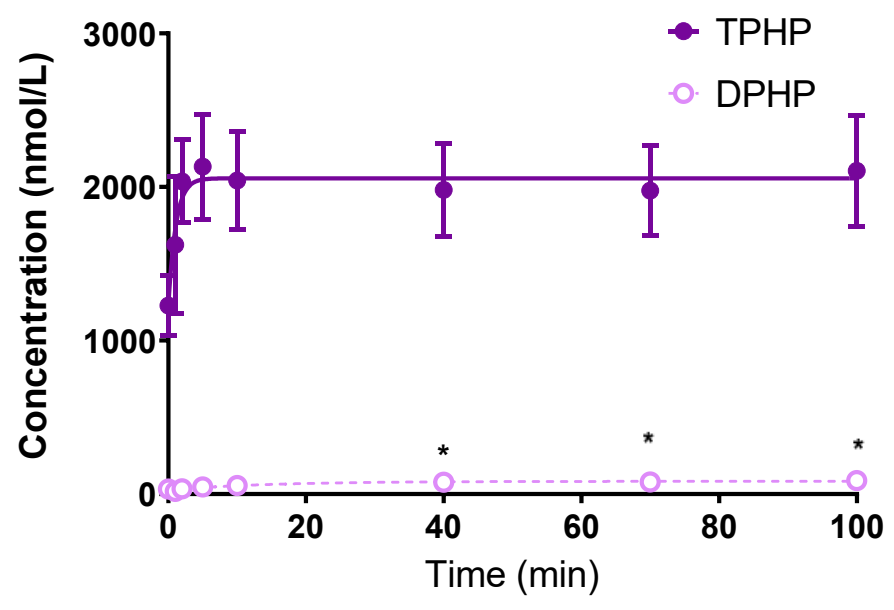

TEP

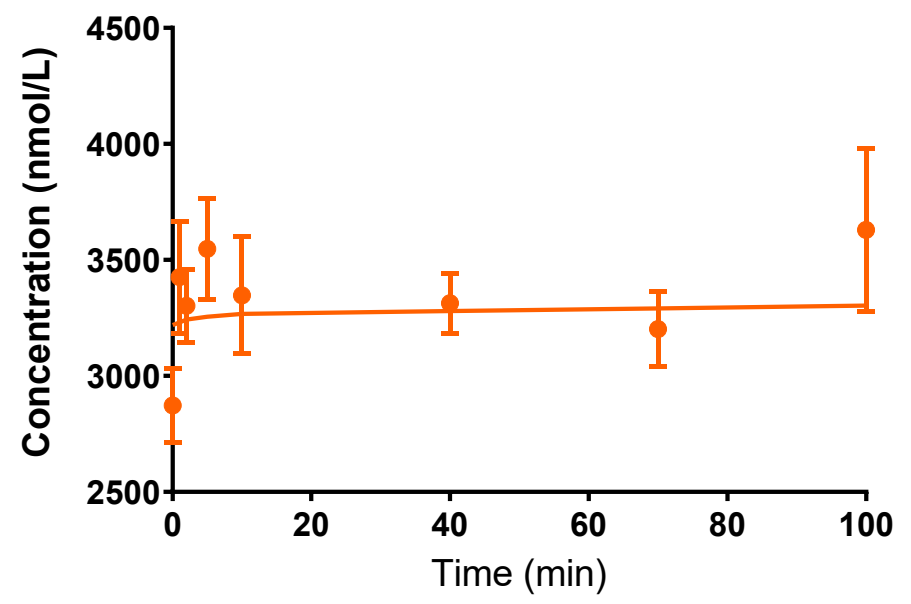

TEHP \& DEHP

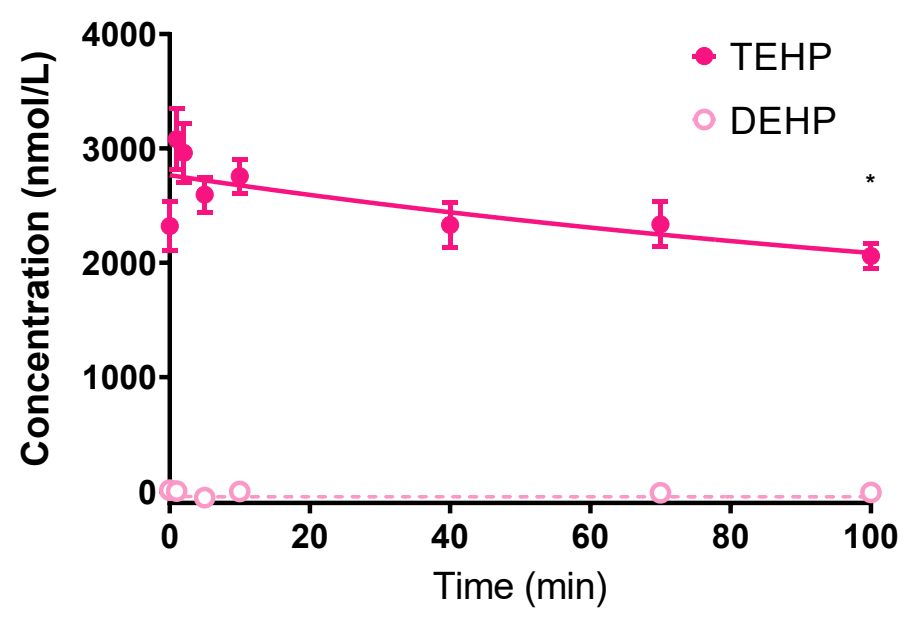




\section{TTBPP \& DPHP}

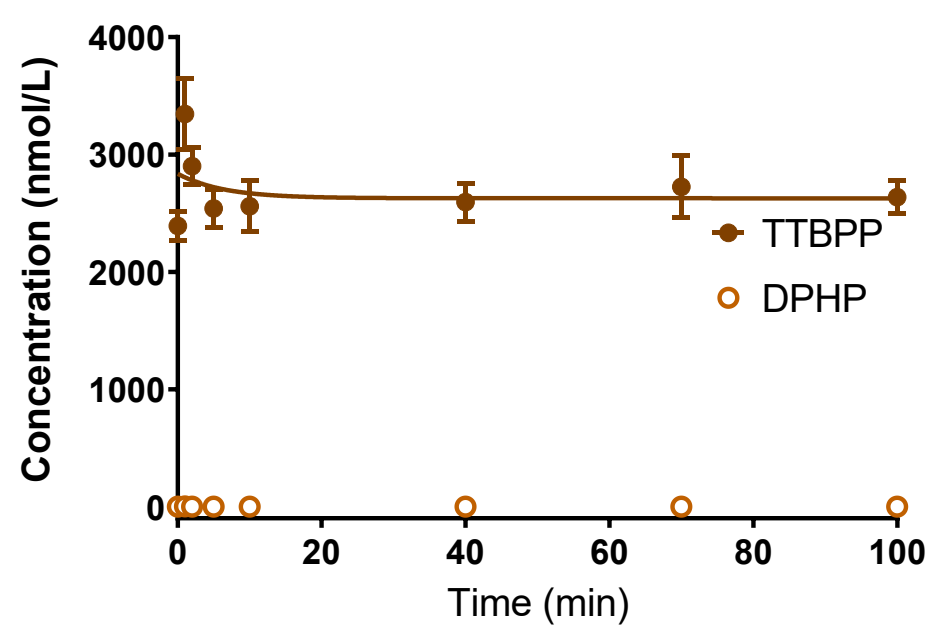

Figure 3.1 In vitro metabolic depletion of OP triesters (solid line and solid symbols) and formation of OP diesters (dashed line and open symbols) over a 100 minute assay with rainbow trout microsomes. Every data point is the mean of triplicate assays $(n=3)$ conducted on $n=2$ days for a total of $n=6$ replicates. Error bars represent the \pm SEM and are omitted where the error bar is shorter than the size of the symbol. The time points when OP triester depletion or OP diester formation significantly differ $(\mathrm{p}<0.05)$ from the concentration at one minute are denoted with an asterisk. The concentration at 1 minute was used instead of the concentration at 0 minutes because it better reflected the dosed concentration.

As demonstrated in Figure 3.1, some OP diester formation occurred, however conversion percentages of OP triester to OP diester were low (Table 3.1). The mass balances suggest that, except for TDCIPP, OP diester formation represents only a portion of converted OP triester in rainbow trout and other metabolites are likely present. While depletion of TBOEP was complete, BBOEP formation was low at $7.4 \%$. TNBP was not depleted as completely or rapidly as TBOEP, and minimal diester was formed $(2.7 \%)$ during the 100 minute incubation period. The in vitro depletion of TBOEP and TNBP and minor formation of their respective diesters, BBOEP and DNBP, in rainbow trout was similarly reported for crucian carp liver microsomes. 
Table 3.1 Organophosphate (OP) triester depletion and OP diester formation in metabolism assays with rainbow trout liver microsomes. Administered concentration of each OP triester was $2 \mu \mathrm{M}$. Names and abbreviations of the OP triesters and OP diesters can be found in Table 1.1.

\begin{tabular}{|c|c|c|c|}
\hline $\begin{array}{c}\text { OP Triester or } \\
\text { Diester }\end{array}$ & $\begin{array}{c}\text { OP Triester } \\
\text { Depletion } \\
(\text { nmol })^{\mathrm{a}}\end{array}$ & $\begin{array}{c}\text { OP Diester } \\
\text { Formation } \\
(\mathbf{n m o l})^{b}\end{array}$ & $\%$ Conversion ${ }^{\mathrm{c}}$ \\
\hline TDCIPP & 141.1 & & \multirow{2}{*}{$-{ }^{d}$} \\
\hline BDCIPP & & 304.7 & \\
\hline TBOEP & 2139.7 & & \multirow{2}{*}{7.4} \\
\hline BBOEP & & 159.1 & \\
\hline TNBP & 768.9 & & \multirow{2}{*}{2.7} \\
\hline DNBP & & 20.8 & \\
\hline TPHP & -69.0 & & \multirow{2}{*}{0} \\
\hline DPHP & & 88.81 & \\
\hline TEHP & 1022.5 & & \multirow{2}{*}{0} \\
\hline DEHP & & -7.9 & \\
\hline TTBPP & 709.3 & & \multirow{2}{*}{0} \\
\hline DPHP & & 0 & \\
\hline
\end{tabular}

${ }^{a}$ Concentration measured at 1 minute minus what remained at 100 minutes

${ }^{\mathrm{b}}$ Concentration quantified at 100 minutes

c $\%$ conversion $=(\mathrm{OP}$ diester formed $) /(\mathrm{OP}$ triester depleted $) \times 100 \%$

$\mathrm{d} \%$ conversion of TDCIPP was not listed since there was no degradation trend in the parent TDCIPP

Using an in vitro microsomal assay, Hou et al. (2018) reported that only $7.1 \%$ of TBOEP was converted to BBOEP and $12.9 \%$ of TNBP was converted to DNBP in crucian carp liver microsomes. Hydroxylated metabolites were predominant, with $43.4 \%$ of TBOEP converted to BBOEHEP and $25.7 \%$ converted to 3-OH-TBOEP. Similarly, $43.1 \%$ of TNBP was converted to the hydroxylated form 3-OH-TNBP. Formation of hydroxylated metabolites of TBOEP and TNBP have also been documented in Chinese rare minnow, 
zebrafish, and human liver microsomes (Hou et al., 2019; Van den Eede et al., 2013a; Wang et al., 2017).

The in vitro rate of TPHP depletion and percent conversion to diester varied among species. Both herring gull and polar bear liver microsomes completely depleted TPHP in a 100 minute assay, however $97 \%$ of TPHP was converted to DPHP in polar bear whereas only 15\% was converted to DPHP in herring gull (Greaves et al., 2016b; Strobel et al., 2018a). Ringed seal showed slow and incomplete depletion with 60\% conversion to DPHP and human liver microsomes had $41 \%$ of TPHP clearance by the end of the 60 minute incubation where DPHP was formed as $22 \%$ of the metabolites (Strobel et al., 2018a; Van den Eede et al., 2013a). This project showed no depletion of TPHP in rainbow trout.

Hydroxylated forms of TPHP have been identified as major metabolites in chicken embryonic hepatocytes and human liver microsomes (Su et al., 2015b; Van den Eede et al., 2013a). In an uptake and depuration study of rainbow trout exposed to TPHP, the liver accumulated the highest residues of TPHP and also exhibited the fastest rate of decrease in concentration during a depuration period (Muir et al., 1980). The authors suggested TPHP metabolism based on the rapid clearance from the liver, however no metabolism was detected in this project. It is possible that TPHP metabolism in rainbow trout may be due to enzymes not present in the microsomal fraction. Branchial elimination and intestinal metabolism have been implicated as contributors to biotransformation of other hydrophobic compounds in rainbow trout including 2-ethylhexyl phthalate, pentachloroethane, and multiple PCBs (Barron et al., 1989; Fitzsimmons et al., 2001).

TTBPP, an alkyl-substituted analogue of TPHP, had minimal metabolism, with no detectable formation of DPHP. Interestingly, while no TPHP depletion was detected, 709.3 
nmol of TTBPP were depleted. The addition of bulky tert-butyl groups on the phenyl rings should increase steric hindrance, leading to a hypothesis that the rate of TTBPP metabolism would be less than the rate of TPHP metabolism. It is possible the additional alkyl groups increased the hydrophobicity of TTBPP, leading to adsorption on glassware and an apparent loss of parent compound (Su et al., 2016a).

In vitro metabolism studies on TEHP are limited. The data that do exist tell a similar story to what is reported here, where TEHP was depleted but no DEHP was detected. Compared to ringed seal and polar bear data, rainbow trout microsomes depleted the most TEHP, around half of the original dosed amount $(1,022.5 \mathrm{nmol})$ whereas ringed seal depleted $226 \mathrm{nmol}$ and polar bear depleted $186 \mathrm{nmol}$ (Strobel et al., 2018a).

Of all the OPEs in this project, TDCIPP was the only OPE to have more diester produced than triester depleted. Herring gull (90\% conversion), polar bear (198\% conversion), ringed seal (276\% conversion), and now rainbow trout (216\% conversion) give an indication that the OP diester BDCIPP is the major metabolite for TDCIPP (Greaves et al., 2016b; Strobel et al., 2018a). In vivo exposure of zebrafish to TDCIPP further supports this where high levels of BDCIPP was detected in the intestine, liver, and gills, indicating complete transformation of TDCIPP to BDCIPP (Wang et al., 2017). Strobel et al. (2018a) has suggested that additional diester produced may be due to endogenous levels of liver OP triester or diester.

Such low percent conversion suggests that there are alternative metabolic pathways in rainbow trout that are responsible for the metabolism of OP triesters. NADPH-dependent phase I enzymes have been implicated in the formation of OP diesters, specifically CYP450 enzymes (Hou et al., 2018; Lindström-Seppä et al., 1981; Van den Eede et al., 2013a). In 
addition to this, recent studies have reported depletion of TPHP and formation of DPHP in the absence of NADPH (Strobel et al., 2018a; Van den Eede et al., 2013a). Depletion of TPHP with no NADPH present varied among species, indicating the contribution of NADPH-independent enzymes in metabolism of TPHP varies and is species-specific.

In an uptake and bioaccumulation study of TPHP in rainbow trout, Muir et al. (1980) suggested TPHP metabolism occurred based on rapid clearance from the liver during the depuration phase of an uptake and depuration experiment. However, this project detected no metabolism of TPHP in rainbow trout microsomes. In vivo experiments exposing goldfish (Casassius auratus), killifish (Oryzias latipes), and zebrafish to TPHP demonstrated species-specific differences in TPHP metabolism where intensive biotransformation occurred in zebrafish and killifish but was very low in goldfish (Sasaki et al., 1981; Wang et al., 2016). Previous studies have identified extrahepatic metabolic activities in both the gills and intestine of rainbow trout, and this latter metabolism can limit the bioavailability of compounds ingested orally (Kleinow et al., 1998; LindströmSeppä et al., 1981; Van Veld et al., 1988). Hou et al. (2018) used intestinal microsomes to investigate in vitro metabolism of TNBP and TBOEP in crucian carp. They detected no significant metabolism of both TNBP and TBOEP, which they suggested was due to lower levels of CYP450 enzymes in intestinal microsomes. However, they concluded their findings cannot be extended to aryl OPEs considering that TPHP is able to be hydrolyzed by serum hydrolases (Van Den Eede et al. 2016b). It is possible that TPHP and other aryl OPEs display metabolism kinetics in the intestine that are distinct and more active than alkyl OPEs. 
In addition to intestinal metabolism, rainbow trout are capable of some branchial metabolism (Barron et al., 1989; Fitzsimmons et al., 2001; Leguen et al., 2000). The role of the gills in accumulation and transformation of OPEs appears to vary among species. Zebrafish exposed to TPHP, TNBP, and TBOEP had detectable levels of metabolites in the gills that were higher than expected on the basis of their lipid contents (Wang et al., 2017; Wang et al., 2016) whereas crucian carp exposed to TNBP and TBOEP had low levels of metabolites but detectable levels of the OP triester parents in the gills (Hou et al., 2019). As the first point of contact for water-borne contaminants, branchial elimination of hydrophobic compounds is important to consider in xenobiotic biotransformation given that presystemic branchial metabolism has been implicated in the elimination of hydrophobic compounds in rainbow trout (Barron et al., 1989; Fitzsimmons et al., 2001).

OPE metabolism in rainbow trout is further compounded by the lack of knowledge regarding the complexity of fish CYP450 enzymes. The function of CYP450 enzymes outside of mammalian systems are not as well understood and is commonly extrapolated from mammalian data. While amino acid sequences may be similar across species, function may vary. In an assessment of CYPs with rainbow trout and killifish, common CYP inducers in mammals such as dexamethasone, pregnenolone-16a-carbonitrile, rifampicin, and fluoxetine are not CYP inducers in rainbow trout, indicating metabolic differences between mammals and fish that should be considered further (Connors et al., 2013; Smith \& Wilson, 2010). Additionally, the genome of rainbow trout is particularly complex. Rainbow trout have been shown to possess more aryl hydrocarbon receptor genes as well as more CYP genes than other fish species, likely a result of tetraploidization during the evolution of the salmonid family (Jönsson et al., 2010). The identification of CYP genes in 
rainbow trout is still an ongoing process, though the potential effect of these additional CYP genes is still unknown. 


\section{Chapter 4: Conclusions and Future Directions}

\subsection{Conclusions}

The overall goal of this thesis was to utilize an in vitro microsomal based metabolism assay to determine the biotransformation of seven OPEs in rainbow trout as a fish model system. The OPEs were selected for this project based on environmental relevance, variance in structure to represent alkyl, aryl, and chlorinated OPEs, as well as the presence of a validated and robust analytical method for quantification of parent triesters and their metabolite diesters (Chu et al., 2011; Chu \& Letcher, 2015).

The in vitro assay was successfully modified to facilitate the use of commercially available rainbow trout microsomes. In general, the OP triester depletion and OP diester formation demonstrated slower OPE metabolism in rainbow trout than what was previously reported for herring gull, ringed seal, and polar bear liver microsomes (Greaves et al., 2016b; Strobel et al., 2018a). A significant factor in the fate of OP triesters is metabolism. In mammalian and avian species, rapid metabolism provided an explanation for the phenomenon of high OPE concentrations in environmental matrices with low OPE tissue residue levels. The degree to which fish are able to metabolize OPEs varies with species and as such, it is possible that compounds not metabolized well by rainbow trout are being transformed lower on the food chain or by other metabolically active tissues such as the intestine or gills (Hou et al., 2018, 2019; Lindström-Seppä et al., 1981; Sasaki et al., 1981; Wang et al., 2017). Rapid metabolism may play a lesser role in the fate of aryl and chlorinated OPEs in a piscine context, leading to a potential to bioaccumulate.

As evidenced from this research and prior studies, the structure of OP triesters influences the rate and extent of metabolism. TNBP and TBOEP have been shown to 
consistently undergo metabolism in rat, herring gull, polar bear, ringed seal, crucian carp, and now rainbow trout liver microsomes, whereas halogenated (TDCIPP) and aryl (TPHP) OPEs have much more variety in the extent to which metabolism occurs (Greaves et al., 2016b; Hou et al., 2018; Sasaki et al., 1984; Strobel et al., 2018a). The degree to which metabolism is influenced by specific species metabolic capabilities and OPE structure is complex and needs to be further investigated.

\subsection{Future Directions}

1) Some efforts have been made to identify enzymes responsible for OPE metabolism. Exposure to OPEs in zebrafish and chicken embryos induced up-regulation of multiple cytochrome P450 enzymes, and more recently, CYP1A, CYP2D6, and CYP3A4 have been identified in crucian carp metabolizing TNBP and TBOEP (Farhat et al., 2013; Hou et al., 2018; Liu et al., 2012). Cytochrome P450 enzymes are a diverse and broad class of enzymes and fish isoforms are not as well understood as mammalian or avian isoforms (Burkina et al., 2017). Further inhibition studies should be performed to further elucidate CYP450 enzymes involved in OPE metabolism. Additionally, the discovery that NADPHindependent enzymes can contribute to OPE metabolism means further work should be done to explicitly identify these enzymes. A better understanding of enzymes facilitating OPE metabolism can improve predictions on the fate of chemicals that are structurally similar and build toward an understanding of the mechanisms behind OPE metabolism. 
2) OP diesters and a variety of hydroxylated compounds have been identified as metabolites of OPEs in multiple species including humans; however, the mass balance in this study show that there are metabolites yet to be identified. Additionally, using a microsomal assay means phase II metabolism was not addressed in this project. The use of non-targeted analysis with high resolution mass spectrometry can be used to identify more transformation products. Further studies using non-targeted analysis y is required to explicitly identify all phase I and phase II metabolites. Identification of metabolites can support biomonitoring efforts. Some metabolites can be formed by an assortment of OPEs, such as DPHP which is a metabolite of TPHP, 2-ethylhexyl diphenyl phosphate (EHDPP), and resorcinol bis(diphenyl phosphate) (RDP), making DPHP an ill-advised choice as a biomarker since the parent OPE would not be able to be determined (Ballesteros-Gómez et al., 2015; Muir \& Grift, 1981). Conversely, OPEs that are not extensively metabolized would make an appropriate choice for biomonitoring (e.g. TEP, TTBPP).

3) There is a paucity of data on the toxicity of OPE metabolites. Given the diversity seen in metabolism of OPEs in mammalian, avian, and piscine models, OP metabolites may be more pervasive in the environment than what was previously thought. There is a need for knowledge of the biological elimination of metabolites as compounds that are poorly eliminated may bioaccumulate and have toxic effects.

4) The use of rainbow trout liver microsomes provided useful information on phase I metabolism of OP triesters and a logical next step is to use hepatocytes to identify phase I and phase II metabolites. Further, while the liver is a solid start for discerning OPE metabolism, other cellular compartments should not be ignored, 
especially in fish where branchial and intestinal metabolism have been documented (Fitzsimmons et al., 2001; Lindström-Seppä et al., 1981). With the identification of phase I and phase II metabolites in rainbow trout, in vivo work with rainbow trout could be done. Not only would this allow for a whole-body understanding the ADME of OPEs in fish, it would be an opportunity to investigate factors that impact metabolic and physiological processes in fish such as body size, sexual maturity, gender, and water temperature (Fitzsimmons et al., 2018).

5) OPE metabolism thus far has focused on species at higher trophic levels. With the discovery of minimal metabolism of multiple OPEs in rainbow trout, it would be interesting to see how successful prey fish are at metabolizing OPEs. Biotransformation rates for the same chemical may vary substantially within and among species (Fitzsimmons et al., 2018), so it is possible that in a piscine context, OPEs are not reaching high trophic levels through dietary means because they are efficiently metabolized by prey fish lower in the food web. Furthermore, OPE metabolism has been studied in organisms that spend all (fish, ringed seal) or a significant portion of their lives (polar bear, herring gull) in or around water. Given recent reports of insects living near an e-waste recycling facility having detectable levels of OPEs (Poma et al., 2019), OPE metabolism in terrestrial feeding species should be addressed. The comparison of OPE metabolism in raptors (Accipitriformes) and songbirds (Passeriformes) could add to the weight of evidence for the fate of OPEs and broaden the scope regarding how OPEs are transformed in a biotic context. 


\section{References}

Abou-Elwafa Abdallah, M., Pawar, G., \& Harrad, S. (2016). Human dermal absorption of chlorinated organophosphate flame retardants; implications for human exposure.

Toxicology and Applied Pharmacology, 291, 28-37.

https://dx.doi.org/10.1016/j.taap.2015.12.004

Ali, N., Eqani, S. A. M. A. S., Ismail, I. M. I., Malarvannan, G., Kadi, M. W., Albar, H. M. S., Rehan, M., Covaci, A. (2016). Brominated and organophosphate flame retardants in indoor dust of Jeddah, Kingdom of Saudi Arabia: Implications for human exposure. Science of the Total Environment, 569-570, 269-277. https://dx.doi.org/10.1016/j.scitotenv.2016.06.093

Alves, A., Covaci, A., Voorspoels, S. (2017). Method development for assessing the human exposure to organophosphate flame retardants in hair and nails.

Chemosphere, 168, 692-698. https://dx.doi.org/10.1016/j.chemosphere.2016.11.006

Andresen, J. A., Grundmann, A., Bester, K. (2004). Organophosphorus flame retardants and plasticisers in surface waters. Science of the Total Environment, 332(1-3), 155166. https://dx.doi.org/10.1016/j.scitotenv.2004.04.021

Arukwe, A., Carteny, C. C., Möder, M., Bonini, A., Maubach, M. A., Eggen, T. (2016). Differential modulation of neuro- and interrenal steroidogenesis of juvenile salmon by the organophosphates - tris(2-butoxyethyl)- and tris(2-cloroethyl) phosphate. Environmental Research, 148, 63-71. https://dx.doi.org/10.1016/j.envres.2016.03.020

Bacaloni, A., Cucci, F., Guarino, C., Nazzari, M., Samperi, R., Laganà, A. (2008). Occurrence of organophosphorus flame retardant and plasticizers in three volcanic lakes of Central Italy. Environmental Science and Technology, 42(6), 1898-1903. https://dx.doi.org/10.1021/es702549g

Ballesteros-Gómez, A., Van den Eede, N., Covaci, A. (2015). In Vitro human metabolism of the flame retardant resorcinol bis(diphenylphosphate) (RDP). Environmental Science \& Technology, 49(6), 3897-3904. https://dx.doi.org/10.1021/es505857e

Barron, M. G., Schultz, I. R., Hayton, W. L. (1989). Presystemic branchial metabolism limits di-2-ethylhexyl phthalate accumulation in fish. Toxicology and Applied Pharmacology, 98(1), 49-57. https://dx.doi.org/10.1016/0041-008X(89)90133-6

Bastiaensen, M., Xu, F., Been, F., Van den Eede, N., Covaci, A. (2018). Simultaneous determination of 14 urinary biomarkers of exposure to organophosphate flame retardants and plasticizers by LC-MS/MS. Analytical and Bioanalytical Chemistry, 1-10. https://dx.doi.org/10.1007/s00216-018-1402-2

Bello, A., Carignan, C. C., Xue, Y., Stapleton, H. M., Bello, D. (2018). Exposure to organophosphate flame retardants in spray polyurethane foam applicators: Role of dermal exposure. Environment International, 113, 55-65. https://dx.doi.org/10.1016/j.envint.2018.01.020

Brandsma, S. H., Leonards, P. E. G., Leslie, H. A., de Boer, J. (2015). Tracing organophosphorus and brominated flame retardants and plasticizers in an estuarine food web. Science of the Total Environment, 505, 22-31. https://dx.doi.org/10.1016/j.scitotenv.2014.08.072

Briels, N., Løseth, M. E., Ciesielski, T. M., Malarvannan, G., Poma, G., Kjærvik, S. A., Léon, A., Cariou, R., Covaci, A., Jaspers, V. L. B. (2018). In ovo transformation of 
two emerging flame retardants in Japanese quail (Coturnix japonica). Ecotoxicology and Environmental Safety, 149, 51-57.

https://dx.doi.org/10.1016/j.ecoenv.2017.10.069

Burkina, V., Rasmussen, M. K., Pilipenko, N., Zamaratskaia, G. (2017). Comparison of xenobiotic-metabolising human, porcine, rodent, and piscine cytochrome P450.

Toxicology, 375, 10-27. https://dx.doi.org/10.1016/J.TOX.2016.11.014

Canbaz, D., Logiantara, A., van Ree, R., van Rijt, L. S. (2017). Immunotoxicity of organophosphate flame retardants TPHP and TDCIPP on murine dendritic cells in vitro. Chemosphere, 177, 56-64.

https://dx.doi.org/10.1016/j.chemosphere.2017.02.149 LK

Cano-Sancho, G., Smith, A., La Merrill, M. A. (2017). Triphenyl phosphate enhances adipogenic differentiation, glucose uptake and lipolysis via endocrine and noradrenergic mechanisms. Toxicology in Vitro, 40, 280-288. https://dx.doi.org/10.1016/j.tiv.2017.01.021

Cao, D., Lv, K., Gao, W., Fu, J., Wu, J., Fu, J., Wang, Y., Jiang, G. (2019). Presence and human exposure assessment of organophosphate flame retardants (OPEs) in indoor dust and air in Beijing, China. Ecotoxicology and Environmental Safety, 169, 383391. https://dx.doi.org/10.1016/j.ecoenv.2018.11.038

Carignan, C. C., McClean, M. D., Cooper, E. M., Watkins, D. J., Fraser, A. J., HeigerBernays, W., Stapleton, H., Webster, T. F. (2013). Predictors of tris(1,3-dichloro-2propyl) phosphate metabolite in the urine of office workers. Environment International, 55, 56-61. https://dx.doi.org/10.1016/j.envint.2013.02.004

Carignan, C. C., Mínguez-Alarcón, L., Butt, C. M., Williams, P. L., Meeker, J. D., Stapleton, H. M., Toth, T., Ford, J. B., Hauser, R. (2017). Urinary concentrations of organophosphate flame retardant metabolites and pregnancy outcomes among women undergoing in vitro fertilization for the EARTH study team. Environmental Health Perspectives, 125(8), 087018. https://dx.doi.org/10.1289/EHP1021

Castro-Jiménez, J., Sempéré, R. (2018). Atmospheric particle-bound organophosphate ester flame retardants and plasticizers in a North African Mediterranean coastal city (Bizerte, Tunisia). Science of the Total Environment, 642, 383-393. https://dx.doi.org/10.1016/j.scitotenv.2018.06.010

Cequier, E., Sakhi, A. K., Marcé, R. M., Becher, G., Thomsen, C. (2015). Human exposure pathways to organophosphate triesters - A biomonitoring study of motherchild pairs. Environment International, 75, 159-165. https://dx.doi.org/10.1016/j.envint.2014.11.009

Chen, G., Jin, Y., Wu, Y., Liu, L., Fu, Z. (2015). Exposure of male mice to two kinds of organophosphate flame retardants (OPFRs) induced oxidative stress and endocrine disruption. Environmental Toxicology and Pharmacology, 40(1), 310-318. https://dx.doi.org/10.1016/j.etap.2015.06.021

Chen, G., Zhang, S., Jin, Y., Wu, Y., Liu, L., Qian, H., Fu, Z. (2015). TPP and TCEP induce oxidative stress and alter steroidogenesis in TM3 Leydig cells. Reproductive Toxicology, 57, 100-110. https://dx.doi.org/10.1016/j.reprotox.2015.05.011

Christia, C., Poma, G., Besis, A., Samara, C., Covaci, A. (2018). Legacy and emerging organophosphorus flame retardants in car dust from Greece: Implications for human exposure. Chemosphere, 196, 231-239. 
https://dx.doi.org/10.1016/j.chemosphere.2017.12.132

Chu, S., Chen, D., Letcher, R. J. (2011). Dicationic ion-pairing of phosphoric acid diesters post-liquid chromatography and subsequent determination by electrospray positive ionization-tandem mass spectrometry. Journal of Chromatography A, 1218(44), 8083-8088. https://dx.doi.org/10.1016/j.chroma.2011.09.011

Chu, S., Letcher, R. J. (2015). Determination of organophosphate flame retardants and plasticizers in lipid-rich matrices using dispersive solid-phase extraction as a sample cleanup step and ultra-high performance liquid chromatography with atmospheric pressure chemical ionization mass . Analytica Chimica Acta, 885, 183-190. https://dx.doi.org/10.1016/j.aca.2015.05.024

Chu, S., Letcher, R. J. (2018, February 2). A mixed-mode chromatographic separation method for the analysis of dialkyl phosphates. Journal of Chromatography A, pp. 63-71. https://dx.doi.org/10.1016/j.chroma.2017.12.069

Clark, A. E., Yoon, S., Sheesley, R. J., Usenko, S. (2017). Spatial and temporal distributions of organophosphate ester concentrations from atmospheric particulate matter samples collected across Houston, TX. Environmental Science and Technology, 51(8), 4239-4247. https://dx.doi.org/10.1021/acs.est.7b00115

Connors, K. A., Du, B., Fitzsimmons, P. N., Hoffman, A. D., Chambliss, C. K., Nichols, J. W., Brooks, B. W. (2013). Comparative pharmaceutical metabolism by rainbow trout (Oncorhynchus mykiss) liver S9 fractions. Environmental Science and Technology, 32(8), 1810-1818. https://dx.doi.org/10.1002/etc.2240

Crump, D., Chiu, S., Kennedy, S. W. (2012). Effects of tris(1,3-dichloro-2-propyl) phosphate and tris(1-chloropropyl) phosphate on cytotoxicity and mRNA expression in primary cultures of avian hepatocytes and neuronal cells. Toxicological Sciences, 126(1), 140-148. https://dx.doi.org/10.1093/toxsci/kfs015

Dasgupta, S., Cheng, V., Vliet, S. M. F., Mitchell, C. A., Volz, D. C. (2018). Tris(1,3dichloro-2-propyl) phosphate exposure during the early-blastula stage alters the normal trajectory of zebrafish embryogenesis. Environmental Science and Technology, 52(18), 10820-10828. https://dx.doi.org/10.1021/acs.est.8b03730

Dasgupta, S., Vliet, S. M., Kupsco, A., Leet, J. K., Altomare, D., Volz, D. C. (2017). Tris(1,3-dichloro-2-propyl) phosphate disrupts dorsoventral patterning in zebrafish embryos. PeerJ, 5, e4156. https://dx.doi.org/10.7717/peerj.4156

Dodson, R. E., Perovich, L. J., Covaci, A., Van Den Eede, N., Ionas, A. C., Dirtu, A. C., Brody, J. G., Rudel, R. A. (2012). After the PBDE phase-out: A broad suite of flame retardants in repeat house dust samples from California. Environmental Science and Technology, 46(24), 13056-13066. https://dx.doi.org/10.1021/es303879n

Dodson, R. E., Rodgers, K. M., Carey, G., Cedeno Laurent, J. G., Covaci, A., Poma, G., Malarvannan, G., Spengler, J. D., Rudel, R. A., Allen, J. G. (2017). Flame retardant chemicals in college dormitories: flammability standards influence dust concentrations. Environmental Science and Technology, 51(9), 4860-4869. https://dx.doi.org/10.1021/acs.est.7b00429

Du, Z., Wang, G., Gao, S., Wang, Z. (2015). Aryl organophosphate flame retardants induced cardiotoxicity during zebrafish embryogenesis: by disturbing expression of the transcriptional regulators. Aquatic Toxicology, 161, 25-32.

https://dx.doi.org/10.1016/j.aquatox.2015.01.027

Eulaers, I., Jaspers, V. L. B., Halley, D. J., Lepoint, G., Nygård, T., Pinxten, R., Covaci, 
A., Eens, M. (2014). Brominated and phosphorus flame retardants in White-tailed Eagle Haliaeetus albicilla nestlings: Bioaccumulation and associations with dietary proxies ( $\delta 13 \mathrm{C}, \delta 15 \mathrm{~N}$ and $\delta 34 \mathrm{~S})$. Science of The Total Environment, 478, 48-57. https://dx.doi.org/10.1016/j.scitotenv.2014.01.051

Evenset, A., Leknes, H., Christensen, G. N., Warner, N., Remberger, M., Gabrielsen, G. W. (2009). Screening of new contaminants in samples from the Norwegian Arctic. NIVA Report 4351-1, SPFO-Report 1049/2009, TA-2510/2009. ISBN: 978-82-4490065-2.

Fabiańska, M. J., Kozielska, B., Konieczyński, J., Bielaczyc, P. (2019). Occurrence of organic phosphates in particulate matter of the vehicle exhausts and outdoor environment - A case study. Environmental Pollution, 244, 351-360. https://dx.doi.org/10.1016/j.envpol.2018.10.060

Faiz, Y., Siddique, N., He, H., Sun, C., Waheed, S. (2018). Occurrence and profile of organophosphorus compounds in fine and coarse particulate matter from two urban areas of China and Pakistan. Environmental Pollution, 233, 26-34. https://dx.doi.org/10.1016/j.envpol.2017.09.091

Fang, Y., Kim, E., Strathmann, T. J. (2018). Mineral- and base-catalyzed hydrolysis of organophosphate flame retardants: potential major fate-controlling sink in soil and aquatic environments. Environmental Science \& Technology, 52(4), 1997-2006. https://dx.doi.org/10.1021/acs.est.7b05911

Farhat, A., Crump, D., Chiu, S., Williams, K. L., Letcher, R. J., Gauthier, L. T., Kennedy, S. W. (2013). In ovo effects of two organophosphate flame retardants-TCPP and TDCPP — on pipping success, development, mRNA expression, and thyroid hormone levels in chicken embryos. Toxicological Sciences, 134(1), 92-102. https://dx.doi.org/10.1093/toxsci/kft100

Fernie, K. J., Chabot, D., Champoux, L., Brimble, S., Alaee, M., Marteinson, S., Chen, D., Palace, V., Bird, D. M., Letcher, R. J. (2017). Spatiotemporal patterns and relationships among the diet, biochemistry, and exposure to flame retardants in an apex avian predator, the peregrine falcon. Environmental Research, 158(May), 4353. https://dx.doi.org/10.1016/j.envres.2017.05.035

Fitzsimmons, P. N., Fernandez, J. D., Hoffman, A. D., Butterworth, B. C., Nichols, J. W. (2001). Branchial elimination of superhydrophobic organic compounds by rainbow trout (Oncorhynchus mykiss). Aquatic Toxicology, 55(1-2), 23-34. https://dx.doi.org/10.1016/S0166-445X(01)00174-6

Fitzsimmons, P. N., Hoffman, A. D., Fay, K. A., Nichols, J. W. (2018). Allometric scaling of hepatic biotransformation in rainbow trout. Comparative Biochemistry and Physiology Part - C: Toxicology and Pharmacology, 214, 52-60. https://dx.doi.org/10.1016/j.cbpc.2018.08.004

Freedonia. (2017). Global Flame Retardants Market. Retrieved from www.freedoniagroup.com

Global flame retardant market projected to reach US\$11.96 billion by 2025. (2017). Additives for Polymers, 2017(1), 10-11. https://dx.doi.org/10.1016/S03063747(17)30014-3

Greaves, A. K., Letcher, R. J., Chen, D., McGoldrick, D. J., Gauthier, L. T., Backus, S. M. (2016). Retrospective analysis of organophosphate flame retardants in herring gull eggs and relation to the aquatic food web in the Laurentian Great Lakes of 
North America. Environmental Research, 150, 255-263.

https://dx.doi.org/10.1016/j.envres.2016.06.006

Greaves, A. K., Su, G., Letcher, R. J. (2016). Environmentally relevant organophosphate triesters in herring gulls: in vitro biotransformation and kinetics and diester metabolite formation using a hepatic microsomal assay. Toxicology and Applied Pharmacology, 308, 59-65. https://dx.doi.org/10.1016/j.taap.2016.08.007

Gu, J., Zhao, M., Zhang, Q., Su, F., Hong, P. (2019). 1H NMR-based metabolomic analysis of nine organophosphate flame retardants metabolic disturbance in HepG2 cell line. Science of The Total Environment, 665, 162-170. https://dx.doi.org/10.1016/j.scitotenv.2019.02.055

Guo, D. F., Batarseh, P., Wong, J., Raphael, D. (2012). Summary of data and findings from testing of a limited number of nail products. Retrieved from https://www.dtsc.ca.gov/GetInvolved/ReviewPanel/upload/DTSC-Summary-ofData-Findings-from-Testing-a-Limited-Number-of-Nail-Products-April-2012.pdf

Guo, H., Zheng, X., Ru, S., Sun, R., Mai, B. (2019). Size-dependent concentrations and bioaccessibility of organophosphate esters (OPEs) in indoor dust: A comparative study from a megacity and an e-waste recycling site. Science of the Total Environment, 650, 1954-1960. https://dx.doi.org/10.1016/j.scitotenv.2018.09.340

Hao, C., Helm, P. A., Morse, D., Reiner, E. J. (2018). Liquid chromatography-tandem mass spectrometry direct injection analysis of organophosphorus flame retardants in Ontario surface water and wastewater effluent. Chemosphere, 191, 288-295. https://dx.doi.org/10.1016/j.chemosphere.2017.10.060

He, C. T., Zheng, J., Qiao, L., Chen, S. J., Yang, J. Z., Yuan, J. G., Yang, Z. Y., Mai, B. $X$. (2015). Occurrence of organophosphorus flame retardants in indoor dust in multiple microenvironments of southern China and implications for human exposure. Chemosphere, 133, 47-52. https://dx.doi.org/10.1016/j.chemosphere.2015.03.043

He, C., Toms, L. M. L., Thai, P., Van den Eede, N., Wang, X., Li, Y., Baduel, C., Harden, F. A., Heffernan, A. L., Hobson, P., Covaci, A., Mueller, J. F. (2018). Urinary metabolites of organophosphate esters: Concentrations and age trends in Australian children. Environment International, 111, 124-130. https://dx.doi.org/10.1016/j.envint.2017.11.019

He, M. J., Lu, J. F., Wei, S. Q. (2019). Organophosphate esters in biota, water, and air from an agricultural area of Chongqing, western China: Concentrations, composition profiles, partition and human exposure. Environmental Pollution, 244, 388-397. https://dx.doi.org/10.1016/j.envpol.2018.10.085

Hill, K. L., Hamers, T., Kamstra, J. H., Willmore, W. G., Letcher, R. J. (2018). Organophosphate triesters and selected metabolites enhance binding of thyroxine to human transthyretin in vitro. Toxicology Letters, 285, 87-93.

https://dx.doi.org/10.1016/j.toxlet.2017.12.030

Hoffman, K., Butt, C. M., Webster, T. F., Preston, E. V., Hammel, S. C., Makey, C., Lorenzo, A. M., Cooper, E. M., Carignan, C., Meeker, J. D., Hauser, R., Soubry, A., Murphy, S. K., Price, T. M., Hoyo, C., Mendelsohn, E., Congleton, J., Daniels, J. L., Stapleton, H. M. (2017). Temporal trends in exposure to organophosphate flame retardants in the United States. Environmental Science and Technology Letters, 4(3), 
112-118. https://dx.doi.org/10.1021/acs.estlett.6b00475

Hoffman, K., Lorenzo, A., Butt, C. M., Hammel, S. C., Henderson, B. B., Roman, S. A., Scheri, R. P., Stapleton, H. M., Sosa, J. A. (2017). Exposure to flame retardant chemicals and occurrence and severity of papillary thyroid cancer: A case-control study. Environment International, 107, 235-242. https://dx.doi.org/10.1016/j.envint.2017.06.021

Hong, X., Chen, R., Hou, R., Yuan, L., Zha, J. (2018). Triphenyl phosphate (TPHP)induced neurotoxicity in adult male Chinese rare minnows (Gobiocypris rarus). Environmental Science \& Technology, acs.est.8b04079. https://dx.doi.org/10.1021/acs.est.8b04079

Hou, R., Huang, C., Rao, K., Xu, Y., Wang, Z. (2018). Characterized in vitro metabolism kinetics of alkyl organophosphate esters in fish liver and intestinal microsomes. Environmental Science and Technology, 52(5), 3202-3210. https://dx.doi.org/10.1021/acs.est.7b05825

Hou, R., Liu, C., Gao, X., Xu, Y., Zha, J., Wang, Z. (2017). Accumulation and distribution of organophosphate flame retardants (PFRs) and their di-alkyl phosphates (DAPs) metabolites in different freshwater fish from locations around Beijing, China. Environmental Pollution, 229, 548-556. https://dx.doi.org/10.1016/j.envpol.2017.06.097

Hou, R., Yuan, S., Feng, C., Xu, Y., Rao, K., Wang, Z. (2019). Toxicokinetic patterns, metabolites formation and distribution in various tissues of the Chinese rare minnow (Gobiocypris rarus) exposed to tri(2-butoxyethyl) phosphate (TBOEP) and tri-nbutyl phosphate (TNBP). Science of the Total Environment, 668, 806-814. https://dx.doi.org/10.1016/j.scitotenv.2019.03.038

Jacobsen, M. L., Jaspers, V. L. B., Ciesielski, T. M., Jenssen, B. M., Løseth, M. E., Briels, N., Eulaers, I., Krogh, A. K. H., Covaci, A., Malarvannan, G., Poma, G., Rigét F. F., Bustnes, J. O., Herzke, D., Gómez-Ramírez, P., Nygård, T., Sonne, C. (2017). Blood clinical-chemical parameters and feeding history in growing Japanese quail (Coturnix japonica) chicks exposed to tris(1,3-dichloro-2-propyl) phosphate and Dechlorane Plus in ovo. Toxicological and Environmental Chemistry, 99(5-6), 938-952. https://dx.doi.org/10.1080/02772248.2017.1293989

Jönsson, M. E., Gao, K., Olsson, J. A., Goldstone, J. V., Brandt, I. (2010). Induction patterns of new CYP1 genes in environmentally exposed rainbow trout. Aquatic Toxicology, 98(4), 311-321. https://dx.doi.org/10.1016/j.aquatox.2010.03.003

Kim, J. W., Isobe, T., Chang, K. H., Amano, A., Maneja, R. H., Zamora, P. B., Siringan, F. P., Tanabe, S. (2011). Levels and distribution of organophosphorus flame retardants and plasticizers in fishes from Manila Bay, the Philippines.

Environmental Pollution, 159(12), 3653-3659. https://dx.doi.org/10.1016/j.envpol.2011.07.020

Kim, U.-J., Wang, Y., Li, W., Kannan, K. (2019). Occurrence of and human exposure to organophosphate flame retardants/plasticizers in indoor air and dust from various microenvironments in the United States. Environment International, 125, 342-349. https://dx.doi.org/10.1016/j.envint.2019.01.065

Kleinow, K. M., James, M. O., Tong, Z., Venugopalan, C. S. (1998). Bioavailability and biotransformation of benzo(a)pyrene in an isolated perfused in situ catfish intestinal preparation. Environmental Health Perspectives, 106(3), 155-166. 
https://dx.doi.org/10.1289/ehp.98106155

Kojima, H., Takeuchi, S., Itoh, T., Iida, M., Kobayashi, S., Yoshida, T. (2013). In vitro endocrine disruption potential of organophosphate flame retardants via human nuclear receptors. Toxicology, 314(1), 76-83. https://dx.doi.org/10.1016/j.tox.2013.09.004

Kojima, H., Takeuchi, S., Van den Eede, N., Covaci, A. (2016). Effects of primary metabolites of organophosphate flame retardants on transcriptional activity via human nuclear receptors. Toxicology Letters, 245, 31-39. https://dx.doi.org/10.1016/j.toxlet.2016.01.004

Kosarac, I., Kubwabo, C., Foster, W. G. (2016). Quantitative determination of nine urinary metabolites of organophosphate flame retardants using solid phase extraction and ultra performance liquid chromatography coupled to tandem mass spectrometry (UPLC-MS/MS). Journal of Chromatography B: Analytical Technologies in the Biomedical and Life Sciences, 1014, 24-30. https://dx.doi.org/10.1016/j.jchromb.2016.01.035

Kurt-Karakus, P., Alegria, H., Birgul, A., Gungormus, E., Jantunen, L. (2018). Organophosphate ester (OPEs) flame retardants and plasticizers in air and soil from a highly industrialized city in Turkey. Science of the Total Environment, 625, 555565. https://dx.doi.org/10.1016/j.scitotenv.2017.12.307

Lee, S., Cho, H.-J., Choi, W., Moon, H.-B. (2018). Organophosphate flame retardants (OPFRs) in water and sediment: Occurrence, distribution, and hotspots of contamination of Lake Shihwa, Korea. Marine Pollution Bulletin, 130, 105-112. https://dx.doi.org/10.1016/J.MARPOLBUL.2018.03.009

Leguen, I., Carlsson, C., Perdu-Durand, E., Prunet, P., Pärt, P., Cravedi, J. P. (2000). Xenobiotic and steroid biotransformation activities in rainbow trout gill epithelial cells in culture. Aquatic Toxicology, 48(2-3), 165-176. https://dx.doi.org/10.1016/S0166-445X(99)00043-0

Lettieri, T., Ghiani, M., Schwesig, D., Tavazzi, S., Haglund, P., Servaes, K., Jarosova, B., Comero, S., Paracchini, B., Blaha, L., Voorspoels, S., Loos, R., Gawlik, B. M., Lindberg, R. H., António, D. C., Carvalho, R., Locoro, G., Fick, J. (2013). EU-wide monitoring survey on emerging polar organic contaminants in wastewater treatment plant effluents. Water Research, 47(17), 6475-6487. https://dx.doi.org/10.1016/j.watres.2013.08.024

Li, H., La Guardia, M. J., Liu, H., Hale, R. C., Mainor, T. M., Harvey, E., Sheng, G., Fu, J., Peng, P. (2019). Brominated and organophosphate flame retardants along a sediment transect encompassing the Guiyu, China e-waste recycling zone. Science of the Total Environment, 646, 58-67. https://dx.doi.org/10.1016/j.scitotenv.2018.07.276

Li, J., Xie, Z., Mi, W., Lai, S., Tian, C., Emeis, K. C., Ebinghaus, R. (2017). Organophosphate esters in air, snow, and seawater in the North Atlantic and the Arctic. Environmental Science and Technology, 51(12), 6887-6896. https://dx.doi.org/10.1021/acs.est.7b01289

Li, R., Wang, H., Mi, C., Feng, C., Zhang, L., Yang, L., Zhou, B. (2019). The adverse effect of TCIPP and TCEP on neurodevelopment of zebrafish embryos/larvae. Chemosphere, 220, 811-817. https://dx.doi.org/10.1016/j.chemosphere.2018.12.198 Li, R., Zhang, L., Shi, Q., Guo, Y., Zhang, W., Zhou, B. (2018). A protective role of 
autophagy in TDCIPP-induced developmental neurotoxicity in zebrafish larvae.

Aquatic Toxicology, 199, 46-54. https://dx.doi.org/10.1016/j.aquatox.2018.03.016

Lindström-Seppä, P., Koivusaari, U., Hänninen, O. (1981). Extrahepatic xenobiotic metabolism in North-European freshwater fish. Comparative Biochemistry and Physiology. Part C, Comparative, 69(2), 259-263. https://dx.doi.org/10.1016/03064492(81)90137-4

Liu, R., Mabury, S. A. (2018). Unexpectedly high concentrations of a newly identified organophosphate ester, tris(2,4-di- tert-butylphenyl) phosphate, in indoor dust from Canada. Environmental Science and Technology, 52(17), 9677-9683. https://dx.doi.org/10.1021/acs.est.8b03061

Liu, X., Cai, Y., Wang, Y., Xu, S., Ji, K., Choi, K. (2019). Effects of tris(1,3-dichloro-2propyl) phosphate (TDCPP) and triphenyl phosphate (TPP) on sex-dependent alterations of thyroid hormones in adult zebrafish. Ecotoxicology and Environmental Safety, 170, 25-32. https://dx.doi.org/10.1016/j.ecoenv.2018.11.058

Liu, X., Ji, K., Choi, K. (2012). Endocrine disruption potentials of organophosphate flame retardants and related mechanisms in H295R and MVLN cell lines and in zebrafish. Aquatic Toxicology, 114, 173-181. https://dx.doi.org/10.1016/j.aquatox.2012.02.019

Liu, X., Ji, K., Jo, A., Moon, H. B., Choi, K. (2013). Effects of TDCPP or TPP on gene transcriptions and hormones of HPG axis, and their consequences on reproduction in adult zebrafish (Danio rerio). Aquatic Toxicology, 134-135, 104-111. https://dx.doi.org/10.1016/j.aquatox.2013.03.013

Liu, Y., Liggio, J., Harner, T., Jantunen, L., Shoeib, M., Li, S. M. (2014). Heterogeneous $\mathrm{OH}$ initiated oxidation: A possible explanation for the persistence of organophosphate flame retardants in air. Environmental Science and Technology, 48(2), 1041-1048. https://dx.doi.org/10.1021/es404515k

Lu, S. Y., Li, Y. X., Zhang, T., Cai, D., Ruan, J. J., Huang, M. Z., Wang, L., Zhang, J. Q., Qiu, R. L. (2017). Effect of e-waste recycling on urinary metabolites of organophosphate flame retardants and plasticizers and their association with oxidative stress. Environmental Science and Technology, 51(4), 2427-2437. https://dx.doi.org/10.1021/acs.est.6b05462

Lu, Z., Martin, P. A., Burgess, N. M., Champoux, L., Elliott, J. E., Baressi, E., De Silva, A. O., de Solla, S. R., Letcher, R. J. (2017). Volatile methylsiloxanes and organophosphate esters in the eggs of European Starlings (Sturnus vulgaris) and congeneric gull species from locations across Canada. Environmental Science \& Technology, 51(17), 9836-9845. https://dx.doi.org/10.1021/acs.est.7b03192

Ma, Y., Cui, K., Zeng, F., Wen, J., Liu, H., Zhu, F., Ouyang, G., Luan, T., Zeng, Z. (2013). Microwave-assisted extraction combined with gel permeation chromatography and silica gel cleanup followed by gas chromatography-mass spectrometry for the determination of organophosphorus flame retardants and plasticizers in biological samples. Analytica Chimica Acta, 786, 47-53. https://dx.doi.org/10.1016/j.aca.2013.04.062

Ma, Y., Salamova, A., Venier, M., Hites, R. A. (2013). Has the phase-out of PBDEs affected their atmospheric levels? Trends of PBDEs and their replacements in the Great Lakes atmosphere. Environmental Science and Technology, 47(20), $11457-$ 
11464. https://dx.doi.org/10.1021/es403029m

Ma, Y., Xie, Z., Lohmann, R., Mi, W., Gao, G. (2017). Organophosphate ester flame retardants and plasticizers in ocean sediments from the North Pacific to the Arctic Ocean. Environmental Science and Technology, 51(7), 3809-3815. https://dx.doi.org/10.1021/acs.est.7b00755

McDonough, C. A., De Silva, A. O., Sun, C., Cabrerizo, A., Adelman, D., Soltwedel, T., Baurfeind, E., Muir, D. C. G., Lohmann, R. (2018). Dissolved organophosphate esters and polybrominated diphenyl ethers in remote marine environments: arctic surface water distributions and net transport through Fram Strait. Environmental Science and Technology, 52(11), 6208-6216. https://dx.doi.org/10.1021/acs.est.8b01127

McGoldrick, D. J., Letcher, R. J., Barresi, E., Keir, M. J., Small, J., Clark, M. G., Sverko, E., Backus, S. M. (2014). Organophosphate flame retardants and organosiloxanes in predatory freshwater fish from locations across Canada. Environmental Pollution, 193, 254-261. https://dx.doi.org/10.1016/j.envpol.2014.06.024

Mendelsohn, E., Hagopian, A., Hoffman, K., Butt, C. M., Lorenzo, A., Congleton, J., Webster, T. F., Stapleton, H. M. (2016). Nail polish as a source of exposure to triphenyl phosphate. Environment International, 86, 45-51. https://dx.doi.org/10.1016/j.envint.2015.10.005

Monclús, L., Lopez-Bejar, M., De la Puente, J., Covaci, A., Jaspers, V. L. B. (2018). First evaluation of the use of down feathers for monitoring persistent organic pollutants and organophosphate ester flame retardants: A pilot study using nestlings of the endangered cinereous vulture (Aegypius monachus). Environmental Pollution, 238, 413-420. https://dx.doi.org/10.1016/j.envpol.2018.03.065

Muir, D. C. G., Grift, N. P. (1981). Environmental dynamics of phosphate esters. II. Uptake and bioaccumulation of 2-ethylhexyl diphenyl phosphate and diphenyl phosphate by fish. Chemosphere, 10(8), 847-855. https://dx.doi.org/10.1016/00456535(81)90084-9

Muir, D. C. G., Grift, N. P., Blouw, A. P., Lockhart, W. L. (1980). Environmental dynamics of phosphate esters. I. Uptake and bioaccumulation of triphenyl phosphate by rainbow trout. Chemosphere, 9(9), 525-532. https://dx.doi.org/10.1016/00456535(80)90068-5

Naccarato, A., Tassone, A., Moretti, S., Elliani, R., Sprovieri, F., Pirrone, N., Tagarelli, A. (2018). A green approach for organophosphate ester determination in airborne particulate matter: Microwave-assisted extraction using hydroalcoholic mixture coupled with solid-phase microextraction gas chromatography-tandem mass spectrometry. Talanta, 189, 657-665. https://dx.doi.org/10.1016/j.talanta.2018.07.077

Ni, Y., Kumagai, K., Yanagisawa, Y. (2007). Measuring emissions of organophosphate flame retardants using a passive flux sampler. Atmospheric Environment, 41(15), 3235-3240. https://dx.doi.org/10.1016/j.atmosenv.2006.10.080

O’Brien, J. W., Thai, P. K., Brandsma, S. H., Leonards, P. E. G., Ort, C., Mueller, J. F. (2015). Wastewater analysis of census day samples to investigate per capita input of organophosphorus flame retardants and plasticizers into wastewater. Chemosphere, 138, 328-334. https://dx.doi.org/10.1016/j.chemosphere.2015.06.014

Oliveri, A. N., Ortiz, E., Levin, E. D. (2018). Developmental exposure to an 
organophosphate flame retardant alters later behavioral responses to dopamine antagonism in zebrafish larvae. Neurotoxicology and Teratology, 67, 25-30. https://dx.doi.org/10.1016/j.ntt.2018.03.002

Ospina, M., Jayatilaka, N. K., Wong, L. Y., Restrepo, P., Calafat, A. M. (2018). Exposure to organophosphate flame retardant chemicals in the U.S. general population: Data from the 2013-2014 National Health and Nutrition Examination Survey.

Environment International, 110, 32-41. https://dx.doi.org/10.1016/j.envint.2017.10.001

Pang, L., Ge, L., Yang, P., He, H., Zhang, H. (2018). Degradation of organophosphate esters in sewage sludge: Effects of aerobic/anaerobic treatments and bacterial community compositions. Bioresource Technology, 255, 16-21. https://dx.doi.org/10.1016/J.BIORTECH.2018.01.104

Pang, L., Yuan, Y., He, H., Liang, K., Zhang, H., Zhao, J. (2016). Occurrence, distribution, and potential affecting factors of organophosphate flame retardants in sewage sludge of wastewater treatment plants in Henan Province, Central China. Chemosphere, 152, 245-251. https://dx.doi.org/10.1016/j.chemosphere.2016.02.104

Pantelaki, I., Voutsa, D. (2019). Organophosphate flame retardants (OPFRs): A review on analytical methods and occurrence in wastewater and aquatic environment. Science of the Total Environment. https://dx.doi.org/10.1016/j.scitotenv.2018.08.286

Persson, J., Wang, T., Hagberg, J. (2018). Organophosphate flame retardants and plasticizers in indoor dust, air and window wipes in newly built low-energy preschools. Science of the Total Environment, 628-629, 159-168. https://dx.doi.org/10.1016/j.scitotenv.2018.02.053

Poma, G., Liu, Y., Cuykx, M., Tang, B., Luo, X. J., Covaci, A. (2019). Occurrence of organophosphorus flame retardants and plasticizers in wild insects from a former ewaste recycling site in the Guangdong province, South China. Science of the Total Environment, 650(Pt 1), 709-712. https://dx.doi.org/10.1016/j.scitotenv.2018.09.067

Preston, E. V., McClean, M. D., Claus Henn, B., Stapleton, H. M., Braverman, L. E., Pearce, E. N., Makey, C. M., Webster, T. F. (2017). Associations between urinary diphenyl phosphate and thyroid function. Environment International, 101, 158-164. https://dx.doi.org/10.1016/j.envint.2017.01.020

Qiao, L., Zheng, X. B., Zheng, J., Lei, W. X., Li, H. F., Wang, M. H., He, C. T., Chen, S. J., Yuan, J. G., Luo, X. J., Yu, Y. J., Yang, Z. Y., Mai, B. X. (2016). Analysis of human hair to assess exposure to organophosphate flame retardants: Influence of hair segments and gender differences. Environmental Research, 148, 177-183. https://dx.doi.org/10.1016/j.envres.2016.03.032

Quintana, J. B., Rodil, R., Reemtsma, T., García-López, M., Rodríguez, I. (2008a). Organophosphorus flame retardants and plasticizers in water and air II. Analytical methodology. TrAC Trends in Analytical Chemistry, 27(10), 904-915. https://dx.doi.org/10.1016/J.TRAC.2008.08.004

Quintana, J. B., Rodil, R., Reemtsma, T., García-López, M., Rodríguez, I. (2008b). Organophosphorus flame retardants and plasticizers in water and air II. Analytical methodology. TrAC - Trends in Analytical Chemistry, 27(10), 904-915. https://dx.doi.org/10.1016/j.trac.2008.08.004

Rantakokko, P., Kumar, E., Braber, J., Huang, T., Kiviranta, H., Cequier, E., Thomsen, C. (2019). Concentrations of brominated and phosphorous flame retardants in 
Finnish house dust and insights into children's exposure. Chemosphere, 223, 99107. https://dx.doi.org/10.1016/j.chemosphere.2019.02.027

Rauert, C., Schuster, J. K., Eng, A., Harner, T. (2018). Global atmospheric concentrations of brominated and chlorinated flame retardants and organophosphate esters. Environmental Science and Technology, 52(5), 2777-2789. https://dx.doi.org/10.1021/acs.est.7b06239

Ren, G., Zheng, K., Zhou, X., Zhang, J., Chu, X., Yu, Z., Zeng, X. (2019). Organophosphate esters in the water, sediments, surface soils, and tree bark surrounding a manufacturing plant in north China. Environmental Pollution, 246, 374-380. https://dx.doi.org/10.1016/j.envpol.2018.12.020

Saeger, V. W., Hicks, O., Kaley, R. G., Michael, P. R., Mieure, J. P., Tucker, E. S. (1979). Environmental fate of selected phosphate esters. Environmental Science and Technology, 13(7), 840-844. https://dx.doi.org/10.1021/es60155a010

Saini, A., Clarke, J., Jariyasopit, N., Rauert, C., Schuster, J. K., Halappanavar, S., Evans, G. J., Su, Y., Harner, T. (2019). Flame retardants in urban air: A case study in Toronto targeting distinct source sectors. Environmental Pollution, 247, 89-97. https://dx.doi.org/10.1016/J.ENVPOL.2019.01.027

Saini, A., Thaysen, C., Jantunen, L., McQueen, R. H., Diamond, M. L. (2016). From clothing to laundry water: Investigating the fate of phthalates, brominated flame retardants, and organophosphate esters. Environmental Science and Technology, 50(17), 9289-9297. https://dx.doi.org/10.1021/acs.est.6b02038

Salamova, A., Hermanson, M. H., Hites, R. A. (2014). Organophosphate and halogenated flame retardants in atmospheric particles from a European Arctic site.

Environmental Science and Technology, 48(11), 6133-6140. https://dx.doi.org/10.1021/es500911d

Salamova, A., Ma, Y., Venier, M., Hites, R. A. (2014). High levels of organophosphate flame retardants in the Great Lakes atmosphere. Environmental Science and Technology Letters, 1(1), 8-14. https://dx.doi.org/10.1021/ez400034n

Sasaki, K., Suzuki, T., Takeda, M., Uchiyama, M. (1984). Metabolism of phosphoric acid triesters by rat liver homogenate. Bulletin of Environmental Contamination and Toxicology, 33(1), 281-288. https://dx.doi.org/10.1007/BF01625544

Sasaki, K., Takeda, M., Uchiyama, M. (1981). Toxicity, Absorption and Elimination of Phosphoric Acid Triesters by Killifish and Goldfish. Bull. Environm. Contam. Toxicol, 27(6), 775-782. Retrieved from https://link-springercom.proxy.library.carleton.ca/content/pdf/10.1007\%2FBF01611095.pdf

Schindler, B. K., Förster, K., Angerer, J. (2009). Determination of human urinary organophosphate flame retardant metabolites by solid-phase extraction and gas chromatography-tandem mass spectrometry. Journal Of Chromatography B Analytical Technologies In The Biomedical And Life Sciences, 877(4), 375-381. https://dx.doi.org/10.1016/j.jchromb.2008.12.030

Schreder, E. D., La Guardia, M. J. (2014). Flame retardant transfers from U.S. households (dust and laundry wastewater) to the aquatic environment. Environmental Science and Technology, 48(19), 11575-11583. https://dx.doi.org/10.1021/es502227h

Schreder, E. D., Uding, N., La Guardia, M. J. (2016). Inhalation a significant exposure route for chlorinated organophosphate flame retardants. Chemosphere, 150, 499- 
504. https://doi.org/10.1016/j.chemosphere.2015.11.084

Shah, M., Meija, J., Cabovska, B., Caruso, J. A. (2006). Determination of phosphoric acid triesters in human plasma using solid-phase microextraction and gas chromatography coupled to inductively coupled plasma mass spectrometry. Journal of Chromatography A, 1103(2), 329-336. https://dx.doi.org/10.1016/j.chroma.2005.11.042

Shen, J., Zhang, Y., Yu, N., Crump, D., Li, J., Su, H., Letcher, R. J., Su, G. (2019). Organophosphate ester, 2-ethylhexyl diphenyl phosphate (EHDPP), elicits cytotoxic and transcriptomic effects in chicken embryonic hepatocytes and its biotransformation profile compared to humans. Environmental Science \& Technology, 53(4), 2151-2160. https://dx.doi.org/10.1021/acs.est.8b06246

Shi, Q., Wang, M., Shi, F., Yang, L., Guo, Y., Feng, C., Liu, J., Zhou, B. (2018). Developmental neurotoxicity of triphenyl phosphate in zebrafish larvae. Aquatic Toxicology, 203, 80-87. https://dx.doi.org/10.1016/j.aquatox.2018.08.001

Shi, Y., Gao, L., Li, W., Wang, Y., Liu, J., Cai, Y. (2016). Occurrence, distribution and seasonal variation of organophosphate flame retardants and plasticizers in urban surface water in Beijing, China. Environmental Pollution, 209, 1-10. https://dx.doi.org/10.1016/j.envpol.2015.11.008

Shoeib, M., Ahrens, L., Jantunen, L., Harner, T. (2014). Concentrations in air of organobromine, organochlorine and organophosphate flame retardants in Toronto, Canada. Atmospheric Environment, 99, 140-147. https://dx.doi.org/10.1016/j.atmosenv.2014.09.040

Shoeib, T., Webster, G. M., Hassan, Y., Tepe, S., Yalcin, M., Turgut, C., Kurt-Karakus, P. B., Jantunen, L. (2019). Organophosphate esters in house dust: A comparative study between Canada, Turkey and Egypt. Science of the Total Environment, 650, 193-201. https://dx.doi.org/10.1016/j.scitotenv.2018.08.407

Slotkin, T. A., Skavicus, S., Stapleton, H. M., Seidler, F. J. (2017). Brominated and organophosphate flame retardants target different neurodevelopmental stages, characterized with embryonic neural stem cells and neuronotypic PC12 cells. Toxicology, 390, 32-42. https://dx.doi.org/10.1016/j.tox.2017.08.009

Smith, E. M., Wilson, J. Y. (2010). Assessment of cytochrome P450 fluorometric substrates with rainbow trout and killifish exposed to dexamethasone, pregnenolone16 $\alpha$-carbonitrile, rifampicin, and $\beta$-naphthoflavone. Aquatic Toxicology, 97(4), 324333. https://dx.doi.org/10.1016/j.aquatox.2010.01.005

Stapleton, H. M., Klosterhaus, S., Eagle, S., Fuh, J., Meeker, J. D., Blum, A., Webster, T. F. (2009). Detection of organophosphate flame retardants in furniture foam and U.S. house dust. Environmental Science and Technology, 43(19), 7490-7495. https://dx.doi.org/10.1021/es9014019

Stockholm Convention Secretariat United Nations Environment. (2017). The $16 \mathrm{New}$ POPs. Stockholm Convention on Persistent Organic Pollutants (POPs), UN Environment, 1-25.

Strobel, A., Letcher, R. J., Willmore, W. G., Sonne, C., Dietz, R. (2018b). Structuredependent in vitro metabolism of alkyl-substituted analogues of triphenyl phosphate in East Greenland polar bears and ringed seals. Environmental Science and Technology Letters, 5(4), 214-219. https://dx.doi.org/10.1021/acs.estlett.8b00064 Strobel, A., Willmore, W. G., Sonne, C., Dietz, R., Letcher, R. J. (2018a). 
Organophosphate esters in East Greenland polar bears and ringed seals: Adipose tissue concentrations and in vitro depletion and metabolite formation. Chemosphere, 196, 240-250. https://dx.doi.org/10.1016/j.chemosphere.2017.12.181

Stubbings, W. A., Guo, J., Simon, K., Romanak, K., Bowerman, W., Venier, M. (2018). Flame retardant metabolites in Addled Bald Eagle eggs from the Great Lakes region. Environmental Science and Technology Letters, 5(6), 354-359. https://dx.doi.org/10.1021/acs.estlett.8b00163

$\mathrm{Su}$, G., Crump, D., Letcher, R. J., Kennedy, S. W. (2014). Rapid in vitro metabolism of the flame retardant triphenyl phosphate and effects on cytotoxicity and mRNA expression in chicken embryonic hepatocytes. Environmental Science and Technology, 48(22), 13511-13519. https://dx.doi.org/10.1021/es5039547

Su, G., Greaves, A. K., Gauthier, L., Letcher, R. J. (2014). Liquid chromatographyelectrospray-tandem mass spectrometry method for determination of organophosphate diesters in biotic samples including Great Lakes herring gull plasma. Journal of Chromatography A, 1374, 85-92. https://dx.doi.org/10.1016/j.chroma.2014.11.022

$\mathrm{Su}$, G., Letcher, R. J., Crump, D., Gooden, D. M., Stapleton, H. M. (2015). In vitro metabolism of the flame retardant triphenyl phosphate in chicken embryonic hepatocytes and the importance of the hydroxylation pathway. Environmental Science and Technology Letters, 2(4), 100-104. https://dx.doi.org/10.1021/acs.estlett.5b00041

Su, G., Letcher, R. J., Moore, J. N., Williams, L. L., Martin, P. A., de Solla, S. R., Bowerman, W. W. (2015). Spatial and temporal comparisons of legacy and emerging flame retardants in herring gull eggs from colonies spanning the Laurentian Great Lakes of Canada and United States. Environmental Research, 142, 720-730. https://dx.doi.org/10.1016/j.envres.2015.08.018

$\mathrm{Su}, \mathrm{G}$. , Letcher, R. J., Yu, H. (2016). Organophosphate flame retardants and plasticizers in aqueous solution: ph-dependent hydrolysis, kinetics, and pathways.

Environmental Science and Technology, 50(15), 8103-8111. https://dx.doi.org/10.1021/acs.est.6b02187

Sühring, R., Diamond, M. L., Scheringer, M., Wong, F., Pućko, M., Stern, G., Burt, A., Hung, H., Fellin, P., Li, H., Jantunen, L. M. (2016). Organophosphate esters in Canadian Arctic air: Occurrence, levels and trends. Environmental Science and Technology, 50(14), 7409-7415. https://dx.doi.org/10.1021/acs.est.6b00365

Sundkvist, A. M., Olofsson, U., Haglund, P. (2010). Organophosphorus flame retardants and plasticizers in marine and fresh water biota and in human milk. Journal of Environmental Monitoring, 12(4), 943-951. https://dx.doi.org/10.1039/b921910b

Takimoto, K., Hirakawa, T., Ito, K., Mukai, T., Okada, M. (1999). Source and transport of tricresyl phosphate (TCP) isomers in Kurose river basin. Atmospheric Environment, 33(19), 3191-3200. https://dx.doi.org/10.1016/S1352-2310(99)000874

Tang, T., Lu, G., Wang, R., Qiu, Z., Huang, K., Lian, W., Tao, X., Dang, Z., Yin, H. (2019). Rate constants for the reaction of hydroxyl and sulfate radicals with organophosphorus esters (OPEs) determined by competition method. Ecotoxicology and Environmental Safety, 170, 300-305. 
https://dx.doi.org/10.1016/j.ecoenv.2018.11.142

Tao, F., Sellström, U., de Wit, C. A. (2019). Organohalogenated flame retardants and organophosphate esters in office air and dust from Sweden. Environmental Science \& Technology, 53(4), 2124-2133. https://dx.doi.org/10.1021/acs.est.8b05269

US EPA. (2007). Report on alternatives to the flame retardant DecaBDE : Evaluation of toxicity, availability, affordability, and fire safety issues. Retrieved from http://www.epa.state.il.us/reports/decabde-study/decabde-alternatives.pdf

Van Den Eede, N., Ballesteros-Gómez, A., Neels, H., Covaci, A. (2016). Does biotransformation of aryl phosphate flame retardants in blood cast a new perspective on their debated biomarkers? Environmental Science and Technology. https://dx.doi.org/10.1021/acs.est.6b03214

Van den Eede, N., Erratico, C., Exarchou, V., Maho, W., Neels, H., Covaci, A. (2015). In vitro biotransformation of tris(2-butoxyethyl) phosphate (TBOEP) in human liver and serum. Toxicology and Applied Pharmacology, 284(2), 246-253. https://dx.doi.org/10.1016/j.taap.2015.01.021

Van den Eede, N., Maho, W., Erratico, C., Neels, H., Covaci, A. (2013). First insights in the metabolism of phosphate flame retardants and plasticizers using human liver fractions. Toxicology Letters, 223(1), 9-15. https://dx.doi.org/10.1016/j.toxlet.2013.08.012

Van den Eede, N., Neels, H., Jorens, P. G., Covaci, A. (2013). Analysis of organophosphate flame retardant diester metabolites in human urine by liquid chromatography electrospray ionisation tandem mass spectrometry. Journal of Chromatography A, 1303, 48-53. https://dx.doi.org/10.1016/j.chroma.2013.06.042

Van den Eede, N., Tomy, G., Tao, F., Halldorson, T., Harrad, S., Neels, H., Covaci, A. (2016). Kinetics of tris (1-chloro-2-propyl) phosphate (TCIPP) metabolism in human liver microsomes and serum. Chemosphere, 144, 1299-1305. https://dx.doi.org/10.1016/j.chemosphere.2015.09.049

van der Veen, I., de Boer, J. (2012). Phosphorus flame retardants: Properties, production, environmental occurrence, toxicity and analysis. Chemosphere. https://dx.doi.org/10.1016/j.chemosphere.2012.03.067

Van Veld, P. A., Patton, J. S., Lee, R. F. (1988). Effect of preexposure to dietary benzo[a]pyrene (BP) on the first-pass metabolism of BP by the intestine of toadfish (Opsanus tau): in vivo studies using portal vein-catheterized fish. Toxicology and Applied Pharmacology, 92(2), 255-265. https://dx.doi.org/10.1016/0041008X(88)90385-7

Verreault, J., Letcher, R. J., Gentes, M. L., Braune, B. M. (2018). Unusually high Deca$\mathrm{BDE}$ concentrations and new flame retardants in a Canadian Arctic top predator, the glaucous gull. Science of the Total Environment, 639, 977-987. https://dx.doi.org/10.1016/j.scitotenv.2018.05.222

Vila-Costa, M., Sebastián, M., Pizarro, M., Cerro-Gálvez, E., Lundin, D., Gasol, J. M., Dachs, J. (2019). Microbial consumption of organophosphate esters in seawater under phosphorus limited conditions. Scientific Reports, 9(1). https://dx.doi.org/10.1038/s41598-018-36635-2

Wang, D., Yan, S., Yan, J., Teng, M., Meng, Z., Li, R., Zhou, Z., Zhu, W. (2019). Effects of triphenyl phosphate exposure during fetal development on obesity and metabolic dysfunctions in adult mice: Impaired lipid metabolism and intestinal dysbiosis. 
Environmental Pollution, 246, 630-638.

https://dx.doi.org/10.1016/j.envpol.2018.12.053

Wang, G., Chen, H., Du, Z., Li, J., Wang, Z., Gao, S. (2017). In vivo metabolism of organophosphate flame retardants and distribution of their main metabolites in adult zebrafish. Science of the Total Environment, 590-591, 50-59. https://dx.doi.org/10.1016/j.scitotenv.2017.03.038

Wang, G., Du, Z., Chen, H., Su, Y., Gao, S., Mao, L. (2016). Tissue-specific accumulation, depuration, and transformation of triphenyl phosphate (TPHP) in adult zebrafish (danio rerio). Environmental Science and Technology, 50(24), 13555-13564. https://dx.doi.org/10.1021/acs.est.6b04697

Wang, G., Shi, H., Du, Z., Chen, H., Peng, J., Gao, S. (2017). Bioaccumulation mechanism of organophosphate esters in adult zebrafish (Danio rerio). Environmental Pollution, 229, 177-187. https://dx.doi.org/10.1016/j.envpol.2017.05.075

Wang, Q., Lai, N. L. S., Wang, X., Guo, Y., Lam, P. K. S., Lam, J. C. W., Zhou, B. (2015). Bioconcentration and transfer of the organophorous flame retardant 1,3dichloro-2-propyl phosphate causes thyroid endocrine disruption and developmental neurotoxicity in zebrafish larvae. Environmental Science and Technology, 49(8), 5123-5132. https://dx.doi.org/10.1021/acs.est.5b00558

Wang, R., Tang, J., Xie, Z., Mi, W., Chen, Y., Wolschke, H., Tian, C., Pan, X., Luo, Y., Ebinghaus, R. (2015). Occurrence and spatial distribution of organophosphate ester flame retardants and plasticizers in 40 rivers draining into the Bohai Sea, north China. Environmental Pollution, 198, 172-178. https://dx.doi.org/10.1016/J.ENVPOL.2014.12.037

Wang, T., Ding, N., Wang, T., Chen, S. J., Luo, X. J., Mai, B. X. (2018).

Organophosphorus esters (OPEs) in $\mathrm{PM}_{2.5}$ in urban and e-waste recycling regions in southern China: concentrations, sources, and emissions. Environmental Research, 167, 437-444. https://dx.doi.org/10.1016/j.envres.2018.08.015

Wang, W., Deng, S., Li, D., Ren, L., Shan, D., Wang, B., Huang, J., Wang, Y., Yu, G. (2018). Sorption behavior and mechanism of organophosphate flame retardants on activated carbons. Chemical Engineering Journal, 332, 286-292. https://dx.doi.org/10.1016/j.cej.2017.09.085

Wang, W., Deng, S., Ren, L., Li, D., Wang, W., Vakili, M., Wang, B., Huang, J., Wang, Y., Yu, G. (2018). Stable covalent organic frameworks as efficient adsorbents for high and selective removal of an aryl-organophosphorus flame retardant from water. ACS Applied Materials and Interfaces, 10(36), 30265-30272. https://dx.doi.org/10.1021/acsami.8b06229

Wang, X., Zhong, W., Xiao, B., Liu, Q., Yang, L., Covaci, A., Zhu, L. (2019). Bioavailability and biomagnification of organophosphate esters in the food web of Taihu Lake, China: Impacts of chemical properties and metabolism. Environment International, 125, 25-32. https://dx.doi.org/10.1016/j.envint.2019.01.018

Wang, Y., Kannan, P., Halden, R. U., Kannan, K. (2019). A nationwide survey of 31 organophosphate esters in sewage sludge from the United States. Science of the Total Environment, 655, 446-453. https://doi.org/10.1016/j.scitotenv.2018.11.224

Wang, Y., Sun, H., Zhu, H., Yao, Y., Chen, H., Ren, C., Wu, F., Kannan, K. (2018). Occurrence and distribution of organophosphate flame retardants (OPFRs) in soil 
and outdoor settled dust from a multi-waste recycling area in China. Science of the Total Environment, 625, 1056-1064.

https://dx.doi.org/10.1016/j.scitotenv.2018.01.013

Wong, F., de Wit, C. A., Newton, S. R. (2018). Concentrations and variability of organophosphate esters, halogenated flame retardants, and polybrominated diphenyl ethers in indoor and outdoor air in Stockholm, Sweden. Environmental Pollution, 240, 514-522. https://dx.doi.org/10.1016/j.envpol.2018.04.086

World Health Organization. (1998). Flame Retardants: Tris(chloropropyl) phosphate and Tris(2-chloroethyl) phosphate. Environmental Health Criteria, 209. Retrieved from https://www.who.int/ipcs/publications/ehc/who_ehc_209.pdf

Yadav, I. C., Devi, N. L., Li, J., Zhang, G. (2018). Organophosphate ester flame retardants in Nepalese soil: Spatial distribution, source apportionment and air-soil exchange assessment. Chemosphere, 190, 114-123.

https://dx.doi.org/10.1016/j.chemosphere.2017.09.112

Yadav, I. C., Devi, N. L., Li, J., Zhang, G., Covaci, A. (2018). Concentration and spatial distribution of organophosphate esters in the soil-sediment profile of Kathmandu Valley, Nepal: Implication for risk assessment. Science of the Total Environment, 613-614, 502-512. https://dx.doi.org/10.1016/j.scitotenv.2017.09.039

Yadav, I. C., Devi, N. L., Singh, V. K., Li, J., Zhang, G. (2019). Measurement of legacy and emerging flame retardants in indoor dust from a rural village (Kopawa) in Nepal: Implication for source apportionment and health risk assessment. Ecotoxicology and Environmental Safety, 168, 304-314. https://dx.doi.org/10.1016/j.ecoenv.2018.10.089

Yan, H., Hales, B. F. (2018). Effects of organophosphate ester flame retardants on endochondral ossification in ex vivo murine limb bud cultures. Toxicological Sciences. https://dx.doi.org/10.1093/toxsci/kfy301

Yan, S., Wu, H., Qin, J., Zha, J., Wang, Z. (2017). Halogen-free organophosphorus flame retardants caused oxidative stress and multixenobiotic resistance in Asian freshwater clams (Corbicula fluminea). Environmental Pollution, 225, 559-568. https://dx.doi.org/10.1016/j.envpol.2017.02.071

Yu, L., Jia, Y., Su, G., Sun, Y., Letcher, R. J., Giesy, J. P., Yu, H., Han, Z., Liu, C. (2017). Parental transfer of tris(1,3-dichloro-2-propyl) phosphate and transgenerational inhibition of growth of zebrafish exposed to environmentally relevant concentrations. Environmental Pollution, 220, 196-203. https://dx.doi.org/10.1016/j.envpol.2016.09.039

Zhang, T., Bai, X. Y., Lu, S. Y., Zhang, B., Xie, L., Zheng, H. C, Jiang, Y. C., Zhou, M. Z., Zhou, Z. Q., Song, S. M., He, Y., Gui, M. W., Ouyang, J. P., Huang, H. B., Kannan, K. (2018). Urinary metabolites of organophosphate flame retardants in China: Health risk from tris(2-chloroethyl) phosphate (TCEP) exposure.

Environment International, 121, 1363-1371. https://dx.doi.org/10.1016/j.envint.2018.11.006

Zhang, W., Wang, P., Li, Y., Wang, D., Matsiko, J., Yang, R., Sun, H., Hao, Y., Zhang, Q., Jiang, G. (2019). Spatial and temporal distribution of organophosphate esters in the atmosphere of the Beijing-Tianjin-Hebei region, China. Environmental Pollution, 244, 182-189. https://dx.doi.org/10.1016/j.envpol.2018.09.131

Zhang, Y., Li, M., Li, S., Wang, Q., Zhu, G., Su, G., Letcher, R. J., Liu, C. (2018). 
Exposure to tris(1,3-dichloro-2-propyl) phosphate for two generations decreases fecundity of zebrafish at environmentally relevant concentrations. Aquatic Toxicology, 200, 178-187. https://dx.doi.org/10.1016/j.aquatox.2018.05.010

Zhang, Y., Su, G., Li, M., Li, S., Wang, Q., Zhu, G., Letcher, R. J., Liu, C. (2018). Chemical and biological transfer: Which one is responsible for the maternal transfer toxicity of tris(1,3-dichloro-2-propyl) phosphate in zebrafish? Environmental Pollution, 243, 1376-1382. https://dx.doi.org/https://doi.org/10.1016/j.envpol.2018.09.114

Zhao, H., Zhao, F., Liu, J., Zhang, S., Mu, D., An, L., Wan, Y., Hu, J. (2018). Trophic transfer of organophosphorus flame retardants in a lake food web. Environmental Pollution, 242, 1887-1893. https://dx.doi.org/10.1016/j.envpol.2018.07.077

Zheng, X., Xu, F., Chen, K., Zeng, Y., Luo, X., Chen, S., Mai, B., Covaci, A. (2015). Flame retardants and organochlorines in indoor dust from several e-waste recycling sites in South China: Composition variations and implications for human exposure. Environment International, 78, 1-7. https://dx.doi.org/10.1016/j.envint.2015.02.006

Zhou, L., Hiltscher, M., Gruber, D., Püttmann, W. (2017). Organophosphate flame retardants (OPFRs) in indoor and outdoor air in the Rhine/Main area, Germany: comparison of concentrations and distribution profiles in different microenvironments. Environmental Science and Pollution Research, 24(12), 1099211005. https://dx.doi.org/10.1007/s11356-016-6902-z

Zhou, L., Püttmann, W. (2019). Distributions of organophosphate flame retardants

(OPFRs) in three dust size fractions from homes and building material markets.

Environmental Pollution, 245, 343-352.

https://dx.doi.org/10.1016/j.envpol.2018.11.023 